OPEN ACCESS

Edited by:

Hansen Wang

University of Toronto, Canada

Reviewed by:

Pamela L. Mellon,

University of California, San Diego,

USA

Wilson C. J. Chung,

Kent State University, USA Giorgio Roberto Merlo,

University of Turin, Italy

*Correspondence:

Csaba Vastagh

vastagh.csaba@koki.mta.hu

Received: 07 July 2016 Accepted: 22 September 2016 Published: 07 October 2016

Citation:

Vastagh C, Rodolosse A, Solymosi N and Liposits Z (2016) Altered

Expression of Genes Encoding

Neurotransmitter Receptors in GnRH Neurons of Proestrous Mice.

Front. Cell. Neurosci. 10:230

doi: 10.3389/fncel.2016.00230

\section{Altered Expression of Genes Encoding Neurotransmitter Receptors in GnRH Neurons of Proestrous Mice}

\author{
Csaba Vastagh ${ }^{1 *}$, Annie Rodolosse $^{2}$, Norbert Solymosi ${ }^{3}$ and Zsolt Liposits ${ }^{1,4}$ \\ ${ }^{1}$ Laboratory of Endocrine Neurobiology, Institute of Experimental Medicine, Hungarian Academy of Sciences, Budapest, \\ Hungary, ${ }^{2}$ Functional Genomics Core, Institute for Research in Biomedicine (IRB Barcelona), Barcelona, Spain, ${ }^{3}$ Department \\ of Animal Hygiene, Herd-Health and Veterinary Ethology, University of Veterinary Medicine, Budapest, Hungary, ${ }^{4}$ Department \\ of Neuroscience, Faculty of Information Technology and Bionics, Pázmány Péter Catholic University, Budapest, Hungary
}

Gonadotropin-releasing hormone $(\mathrm{GnRH})$ neurons play a key role in the central regulation of reproduction. In proestrous female mice, estradiol triggers the pre-ovulatory $\mathrm{GnRH}$ surge, however, its impact on the expression of neurotransmitter receptor genes in $\mathrm{GnRH}$ neurons has not been explored yet. We hypothesized that proestrus is accompanied by substantial changes in the expression profile of genes coding for neurotransmitter receptors in $\mathrm{GnRH}$ neurons. We compared the transcriptome of $\mathrm{GnRH}$ neurons obtained from intact, proestrous, and metestrous female GnRH-GFP transgenic mice, respectively. About 1500 individual $\mathrm{GnRH}$ neurons were sampled from both groups and their transcriptome was analyzed using microarray hybridization and real-time PCR. In this study, changes in mRNA expression of genes involved in neurotransmitter signaling were investigated. Differential gene expression was most apparent in GABA-ergic (Gabbr1, Gabra3, Gabrb3, Gabrb2, Gabrg2), glutamatergic (Gria1, Gria2, Grin1, Grin3a, Grm1, Slc17a6), cholinergic (Chrnb2, Chrm4) and dopaminergic (Drd3, Drd4), adrenergic (Adra1b, Adra2a, Adra2c), adenosinergic (Adora2a, Adora2b), glycinergic (G/ra), purinergic (P2rx7), and serotonergic (Htr1b) receptors. In concert with these events, expression of genes in the signaling pathways downstream to the receptors, i.e., G-proteins (Gnai1, Gnai2, Gnas), adenylate-cyclases (Adcy3, Adcy5), protein kinase A (Prkaca, Prkacb) protein kinase C (Prkca) and certain transporters (Slc1a4, Slc17a6, Slc6a17) were also changed. The marked differences found in the expression of genes involved in neurotransmitter signaling of $\mathrm{GnRH}$ neurons at pro- and metestrous stages of the ovarian cycle indicate the differential contribution of these neurotransmitter systems to the induction of the pre-ovulatory $\mathrm{GnRH}$ surge, the known prerequisite of the subsequent hormonal cascade inducing ovulation.

Keywords: GnRH neuron, gene expression, proestrus, neurotransmission, genomics, microarray analysis, pathway analysis, mouse 


\section{INTRODUCTION}

Gonadotropin-releasing hormone $(\mathrm{GnRH})$ neurons play a fundamental role in the maintenance of reproduction (Knobil and Neill, 2006). GnRH axons project to the median eminence where they release (Merchenthaler et al., 1980) GnRH into the portal circulation to regulate the pituitary-gonadal axis (Carmel et al., 1976). GnRH neurons are controlled by different neuronal networks via specific membrane receptors for neurotransmitters and neuropeptides released from the presynaptic neuronal afferents (Smith and Jennes, 2001; Campbell, 2007) that modulate the synthesis rate and release pattern of GnRH and other coproduced neuromodulators (Finn et al., 1998; Christian and Moenter, 2010). The operation of the hypothalamo-pituitary gonadal (HPG) axis is cyclic including the cellular activity of GnRH neurons (Plant, 2015). Gonadal hormones have a substantial role in the modulation of GnRH neurons and their neuronal afferents (Radovick et al., 2012).

In female rodents, estradiol (E2) exerts biphasic effects on GnRH neurons and the release of the decapeptide (Sarkar and Fink, 1980; Herbison, 1998). It predominantly suppresses the GnRH system via negative feedback effects with the exception of proestrus when the rising level of E2 primes the system for the preovulatory GnRH surge (Sarkar et al., 1976). This process is driven by $\mathrm{E} 2$ acting on estrogen receptors $(\mathrm{ER} \alpha$, ER $\beta$, GPR30 and STX-sensitive membrane receptors; Chu et al., 2009; Terasawa et al., 2009; Kenealy et al., 2011; Moenter and $\mathrm{Chu}, 2012$ ). While the afferent systems of GnRH neurons are known to be regulated predominantly by $\mathrm{ER} \alpha$ (Wintermantel et al., 2006; Christian et al., 2008; Yeo and Herbison, 2014; Cheong et al., 2015), GnRH neurons express exclusively the beta subtype of the nuclear receptor (Hrabovszky et al., 2000, 2001). The positive E2 feedback, therefore, can target the widespread neuronal regulators of the GnRH system and also the GnRH neurons themselves via direct actions. The neuronal networks mediating the negative and positive feedback effects of E2 to GnRH neurons have been extensively studied by morphological and functional tools (Wintermantel et al., 2006; Christian et al., 2008; Yeo and Herbison, 2014). In the preovulatory GnRH surge period, GnRH neurons undergo activation exemplified by expression of the immediate early gene c-Fos (Lee et al., 1990), increased transcriptional activity (Chiu et al., 1988; Wang et al., 1995), induction of hormone synthesis (Gore and Roberts, 1997; Finn et al., 1998) and altered firing pattern (Christian et al., 2005; Farkas et al., 2013).

The classical neurotransmitter systems of the brain are potent regulators of the GnRH system as reviewed earlier (Smith and Jennes, 2001). Powerful regulatory role has been revealed for gamma-aminobutyric acid (GABA) (Herbison and Moenter, 2011), glutamate (Iremonger et al., 2010) dopamine (DA) (Liu and Herbison, 2013), norepinephrine (NE) (Hosny and Jennes, 1998), serotonin (Bhattarai et al., 2014), acetylcholine (ACh) (Turi et al., 2008), and histamine (H) (Fekete et al., 1999). In concert with the rich communication of GnRH neurons with diverse transmitter systems of the brain, the expression of genes encoding for neurotransmitter receptors (Todman et al., 2005) and ion channels (Bosch et al., 2013; Norberg et al.,
2013) in GnRH neurons has also been verified. In the present study, the proestrus-associated changes in the expression of neurotransmitter receptor genes of GnRH neurons have been challenged. To achieve this goal, we carried out microarray- and PCR-based transcriptome analysis of GnRH neurons harvested from regularly cycling GnRH-GFP transgenic mice at proestrus and metestrus stages of the ovarian cycle. The comparative study revealed a differential expression of neurotransmitter receptor genes of GnRH neurons in proestrous mice providing novel data to have a better understanding of the communication and plasticity between GnRH neurons and their afferents under the positive feedback action of estradiol.

\section{MATERIALS AND METHODS}

\section{Ethics Statement}

All experiments were performed with permissions from the Animal Welfare Committee of the Institute of Experimental Medicine Hungarian Academy of Sciences (Permission Number: A5769-01) and in accordance with legal requirements of the European Community (Decree86/609/EEC). All animal experimentation described was conducted in accordance with accepted standards of humane animal care and all efforts were made to minimize suffering.

\section{Animals}

Adult, gonadally intact female mice were used from local colonies bred at the Medical Gene Technology Unit of the Institute of Experimental Medicine (IEM). They were housed in light (12:12 light-dark cycle, lights on at 06:00 h) - and temperature (22 \pm $2{ }^{\circ} \mathrm{C}$ ) controlled environment, with free access to standard food and tap water. GnRH-green-fluorescent protein (GnRH-GFP) transgenic mice (Suter et al., 2000) bred on a C57BL/6J genetic background were used. In this animal model, a GnRH promoter segment drives selective GFP expression in the majority of GnRH neurons. The estrous cycle was monitored daily between 9 and 10 a.m. by microscopic evaluation of vaginal cytology (Nelson et al., 1982; Byers et al., 2012; Cora et al., 2015). Proestrous ( $n=6)$ and metestrous $(n=6)$ female mice with at least two consecutive, regular estrous cycles were used. In order to avoid the possible circadian effect, animals were sacrificed at the same period of the day, between 16:00 and 18:00 h. Those animals were considered to be in the proestrus stage that fulfilled the following criteria: (1) vaginal smear staining with predominance of nucleated epithelial cells (Byers et al., 2012); (2) LH serum concentrations $>5 \mathrm{mg} / \mathrm{L}$ $(15.11 \pm 3.4 \mathrm{mg} / \mathrm{L})$; (3) uterus wet weights $>0.15 \mathrm{~g}(0.19 \pm$ $0.01 \mathrm{~g})$. Accordingly, the following criteria were applied for the metestrous cycle phase: (1) vaginal smears consisting of the three cell types: leukocytes, cornified and nucleated epithelial cells (Byers et al., 2012); (2) serum LH levels $<0.5 \mathrm{mg} / \mathrm{L}(0.35$ $\pm 0.02 \mathrm{mg} / \mathrm{L})$; (3) uterus wet weights $<0.1 \mathrm{~g}(0.08 \pm 0.01 \mathrm{~g})$. Serum LH concentrations and uterus weight data are presented in Supplementary Figure 1.

\section{Serum LH Measurements}

Blood samples were collected from the heart of deeply anesthetized mice immediately before the brain fixation step. 
The samples were chilled on ice, centrifuged at $1300 \mathrm{~g}$ for $3 \mathrm{~min}$ at $4^{\circ} \mathrm{C}$. Plasma was aspirated then frozen and stored at $-80^{\circ} \mathrm{C}$ until further use. Serum $\mathrm{LH}$ concentrations were measured with a rodent LH ELISA kit \#ERK R7010 from Endocrine Technologies Inc. (Newark, CA, USA) according to manufacturers' instructions.

\section{Laser Capture Microdissection}

Brain fixation, preparation of sections for the subsequent laser capture microdissection (LCM) and microarray profiling were performed as reported elsewhere (Khodosevich et al., 2007; Vastagh et al., 2015). Briefly, metestrous $(n=6)$ and proestrous female $(n=6)$ mice were deeply anesthetized and perfused transcardially with $80 \mathrm{ml} 0.5 \%$ paraformaldehyde followed by $20 \%$ sucrose. For microdissection, $7 \mu \mathrm{m}$ thick coronal brain sections were cut. Sections were mounted on PEN-membrane slides (Zeiss, Jena, Germany), processed further for laser microdissection. Uniform and representative sampling of the entire GnRH neuronal population was performed using LCM performed on a PALM Microbeam system (Carl Zeiss Microimaging Gmbh, Jena, Germany) which was equipped with an epifluorescent setup. About 250 GFP-positive neurons were dissected per animal from 80 to 100 consecutive sections to generate $\mathrm{GnRH}$ cell samples from each brain.

\section{RNA Isolation}

GnRH cell samples (metestrous: $n=6$, proestrous: $n=6$ ) collected with LCM were incubated in $200 \mathrm{ml}$ lysis buffer at $56^{\circ} \mathrm{C}$ for $3 \mathrm{~h}$. RNA was isolated from the lysate by proteinase $\mathrm{K} /$ acid phenol method (Khodosevich et al., 2007), then precipitated by adding isopropanol (Sigma-Aldrich) and $20 \mu \mathrm{g}$ glycogen (Thermo Fischer Scientific, Waltham, MA, USA) at $-20^{\circ} \mathrm{C}$ for $30 \mathrm{~min}$ followed by centrifugation at $14,000 \mathrm{~g}$ at $4^{\circ} \mathrm{C}$. The pellet was washed in $70 \%$ ethanol, air-dried and resuspended in water. The remaining genomic DNA was eliminated by treatment the mixture with $1 \mathrm{U}$ of RNase-free DNase-I (Thermo Fischer Scientific). RNA was purified using RNeasy MinElute Cleanup kit (Qiagen, Hilden, Germany). Total RNA was eluted with $14 \mu \mathrm{l}$ of ribonuclease-free water. For the analysis of RNA integrity, RNA was isolated from the tissue of the medial preoptic area, and measured using RNA Pico Chip on the 2100 Bioanalyzer (Agilent, Santa Clara, CA, US; Supplementary Figure 2A).

\section{Whole Transcriptome Amplification (WTA)}

Library preparation and amplification were performed according to the manufacturer's instructions for the WTA2 kit (SigmaAldrich). In the first step of the WTA2 protocol, the RNA was reverse transcribed implementing non self-complementary and quasi-random $3^{\prime}$ and universal $5^{\prime}$ primers. The newly synthetized single strands were the templates for annealing and extension steps. When the SYBR Green signal reached a plateau, the reaction was stopped. The resultant library contained cDNA fragments with size distribution between 100 and 1000 base pairs (data obtained from Agilent Bioanalyzer using DNA 1000 microfluidic chip; Supplementary Figure 2B). The amplified double-stranded cDNA was purified and quantified on a Nanodrop ND-1000 spectrophotometer (Thermo Fisher Scientific).

\section{Mouse Genome 430 PM Arrays}

Eight microgram of cDNA was fragmented by DNase I and biotinylated by terminal transferase obtained from the GeneChip Mapping 250K Nsp Assay Kit (Affymetrix Inc., Santa Clara, CA, USA). Hybridization, washing, staining, and scanning of Affymetrix Mouse Genome 430 PM Strip arrays were performed following the manufacturer's recommendations. The Mouse Genome 430 PM Strip array allows the analysis of 34,325 wellannotated genes using 45,123 distinct probe sets. Scanned images (DAT files) were transformed into intensities (CEL files) using the AGCC software (Affymetrix). RMA analysis was performed by means of the statistical analysis software Partek Genomics Suite (Partek Inc., St. Louis, MO, USA) to obtain probe set level expression estimates.

\section{Bioinformatics and Pathway Analysis}

All statistical and data mining works were performed in R-environment ( $\mathrm{R}$ Core Team, 2016) with Bioconductor packages (Huber et al., 2015). Quality assessment of microarrays $(n=12)$ was performed using affyQCReport (Kauffmann et al., 2009). For quality control data regarding RNA integrity, see Supplementary Figure 3. Raw microarray data were preprocessed for analysis using RMA (Robust Multi-Array Average (Irizarry et al., 2003). Fold change (FC) estimation and difference analysis of gene expression were based on linear models combined with Bayesian methods using limma package (Ritchie et al., 2015). FC was calculated from normalized and $\log _{2}$ transformed gene expression microarray data for each probe sets. The obtained $p$-values were adjusted by the FDR-based method. The following cut-off criteria were applied on the differentially expressed genes (DEG): $|\mathrm{FC}|>1.6$; and adjusted $p$-value $\left(p_{\text {adj }}\right)$ $<0.05$. The top 10 differentially expressed genes (up- and downregulated in proestrus, respectively) are shown in Supplementary Table 1.

For over-representation analysis, the list of DEGs was analyzed using the web-based functional annotation tool DAVID Bioinformatics Resources 6.7 (https://david.ncifcrf.gov) at default settings (Huang da et al., 2009a,b).

For visualization of biological pathways, the data matrix of $\log _{2}$ transformed and RMA-normalized microarray data were analyzed using a public web server Graphite Web (Sales et al., 2013). Of the available analytical methods, Signaling Pathway Impact Analysis (SPIA) was used. Over the classical probabilistic components, the SPIA also applies statistical systems biology approaches: it takes into consideration (1) the extent of the expression changes of each gene (2) the position of the DEG within a pathway, (3) the topology of the pathway, (4) the type of interaction between the genes to identify significantly impacted pathways where the total net accumulated perturbation in the pathway (tA) can be calculated (Tarca et al., 2009) The level of significance was 0.05 using FDR correction. Interacting genes of the significant neurotransmitter signaling pathways (pGFDR $<$ 0.05) were visualized using Cytoscape (ver. 3.2.1) open source software platform. 


\section{Quantitative Real-Time PCR Studies}

For quantitative real-time PCR (qPCR) investigations of LCMderived GnRH samples (proestrous females $n=6$, metestrous females $n=5$ ) RNA isolation and WTA were performed as described in the previous section. Amplified and column-purified cDNA was used as template for qPCR. Whole transcriptomeamplified cDNA from LCM samples were diluted in $0.1 \mathrm{x}$ TE buffer for qPCR investigation. Inventoried TaqMan assays were used to confirm microarray results by qPCR. Each assay consisted of a FAM dye-labeled TaqMan MGB probe and two PCR primers. Thermal cycling conditions of the qPCR were as follows: $2 \mathrm{~min}$ at $50^{\circ} \mathrm{C}$ and $10 \mathrm{~min}$ at $95^{\circ} \mathrm{C}$, followed by 40 cycles of $15 \mathrm{~s}$ at $95^{\circ} \mathrm{C}$ and $1 \mathrm{~min}$ at $60^{\circ} \mathrm{C}$ using ViiA 7 real-time PCR platform (Thermo Fisher Scientific). Differential expression of genes was calculated by the $2^{-\Delta \Delta \mathrm{Ct}}$ method (Livak and Schmittgen, 2001) using GAPDH gene as a reference. Student's $t$-test were used as a statistical method in comparison of gene expression of the two groups (proestrus: $n=6$; metestrus: $n=5$ ).

\section{RESULTS}

In this study, we analyzed characteristic changes in neurotransmitter signaling of $\mathrm{GnRH}$ neurons-regulation of receptor subunits and downstream elements of the signaling cascades at the level of gene expression-by comparison of the neurotransmitter signaling-related elements of the whole transcriptome of GnRH neurons obtained from intact, metestrous and proestrous GnRH-GFP transgenic mice, respectively.

\section{Over-Representation Analysis}

The functional annotation tool DAVID Bioinformatics Resources was used to discover the most relevant gene ontology (GO) annotations. GO categories were differentially represented (FDR adjusted $p<0.05)$ as follows: GO:0005874 microtubule, GO:0000166 nucleotide binding; GO:0016071 mRNA metabolic process; GO:0031988 membrane-bounded vesicle; GO:0007268 synaptic transmission; GO:0044456 synapse part.

\section{Differential Expression of Genes Involved in Neurotransmitter Signaling}

Analysis of microarray data revealed differentially expressed genes associated with various neurotransmitter signaling mechanisms. Receptor subunits of GABAergic, glutamatergic, and cholinergic communication, as well as receptors participating in adrenergic, serotonergic, dopaminergic, glycinergic, adenosinergic, and purinergic neurotransmission exhibited significant changes $(\mathrm{FC}>1.6$; adjusted $p<0.05)$ in gene expression levels. In addition, genes encoding G-proteins and downstream effectors as well as neurotransmitter/amino acid transporters of the solute carrier family also showed differential expression (Figure 1 and Table 1).

Significant downregulation was found in gene expression of adenosinergic (Adora2a, Adora2b), adrenergic (Adra1b, Adra2a, Adra2c) serotonergic (Htr1b), purinergic (P2rx7), and cholinergic (Chrm4, Chrne) receptors or their subunits, respectively, by microarray data analysis. Similarly, the dopaminergic receptor Drd3 and Drd4 exhibited lower mRNA level in proestrus. The Gabbr1 coding for GABA-B receptor 1 and the GABA-A receptor subunit Gabra3, Gabrb2, Gabrb3, Gabrd, Gabrg2 were upregulated. The gene of the GABA-A receptor associated protein, Gabarap were also upregulated. Other GABA-A receptor subunit, the Gabrd showed downregulated gene expression. Receptor subunits of the glutamatergic signaling were upregulated (Grin3a, Grial, Gria2, and Grin1) whereas Grin2d, the metabotropic glutamate receptor Grm1 and glutaminase $(G l s)$ were downregulated. The expression level of the nicotinic cholinergic receptor beta polypeptide 2 (Chrnb2), as well as several heterotrimeric G-protein alpha subunits (Gnai1, Gnai2, and Gnas) were increased. Genes of downstream primary effector proteins were expressed at either higher $(A d c y 5)$ or lower level (Adcy3, Plcb2) in proestrus. The secondary effector Prkaca, Prkacb, and Prkca were upregulated. As far as the solute carrier families are concerned, the glutamate Slc1a4, the vesicular glutamate transporter Slc17a6 and sodium-dependent vesicular transporter Slc6a17 exhibited higher expression level in GnRH neurons in proestrus. Expression of Clcn6 and Glra1 genes, both involved in cellular chloride ion transport, were up- or down-regulated, respectively.

\section{Validation of the Microarray Data}

TaqMan real-time PCR was used for validation of microarray data (Figure 2A). Out of the 9 selected target genes, representing GABA, glutamate and acetylcholine neurotransmission, the differential expression of 8 genes was confirmed (Slc17a6, Grin1, Gria1, Chrnb2, Gabrb2, Gabbr1, Gabrb3, Gabra3) and 6 of them exhibited FC >1.5 (Slc17a6, Grin1, Gria1, Chrnb2, Gabrb2, and Gabbr1). We found significant differences in gene expression of GABAB1 and Slc17a6 genes by qPCR. Differences between other targets were not significant due to the high standard deviation of individual samples. The correlation coefficient (Pearson's $r=-0.8445)$ indicates the quantitative interrelation between microarray and real-time PCR data (Figure 2B).

\section{Pathway Analyses}

High throughput analysis of microarray data from 6 proestrous and 6 metestrous females by Signaling Pathway Impact Analysis (False Discovery Rate, FDR of DEGs < 0.05) identified 32 KEGG and 34 REACTOME pathways (adjusted pG using FDR, pGFdr $<0.05$ ). Three of the KEGG pathways (GABAergic, cholinergic, and dopaminergic signaling) and two of the REACTOME pathways (Neurotransmitter receptor binding and downstream transmission in the postsynaptic cell; Activation of NMDA receptor upon glutamate binding and postsynaptic events) were strongly associated with neurotransmitter signaling and/or its postsynaptic events (Table 2).

\section{GABAergic Signaling}

The "GABAergic synapse" KEGG pathway (pGFdr $=5.10 \mathrm{E}$ 03) was stated as inhibited (observed value of the perturbation score, $\mathrm{tA}=-4.555)$ and involved 25 differentially expressed genes (Table 2). In proestrus, subunits of the GABA-A receptor showed altered gene expression level (up-regulated: Gabra3, 


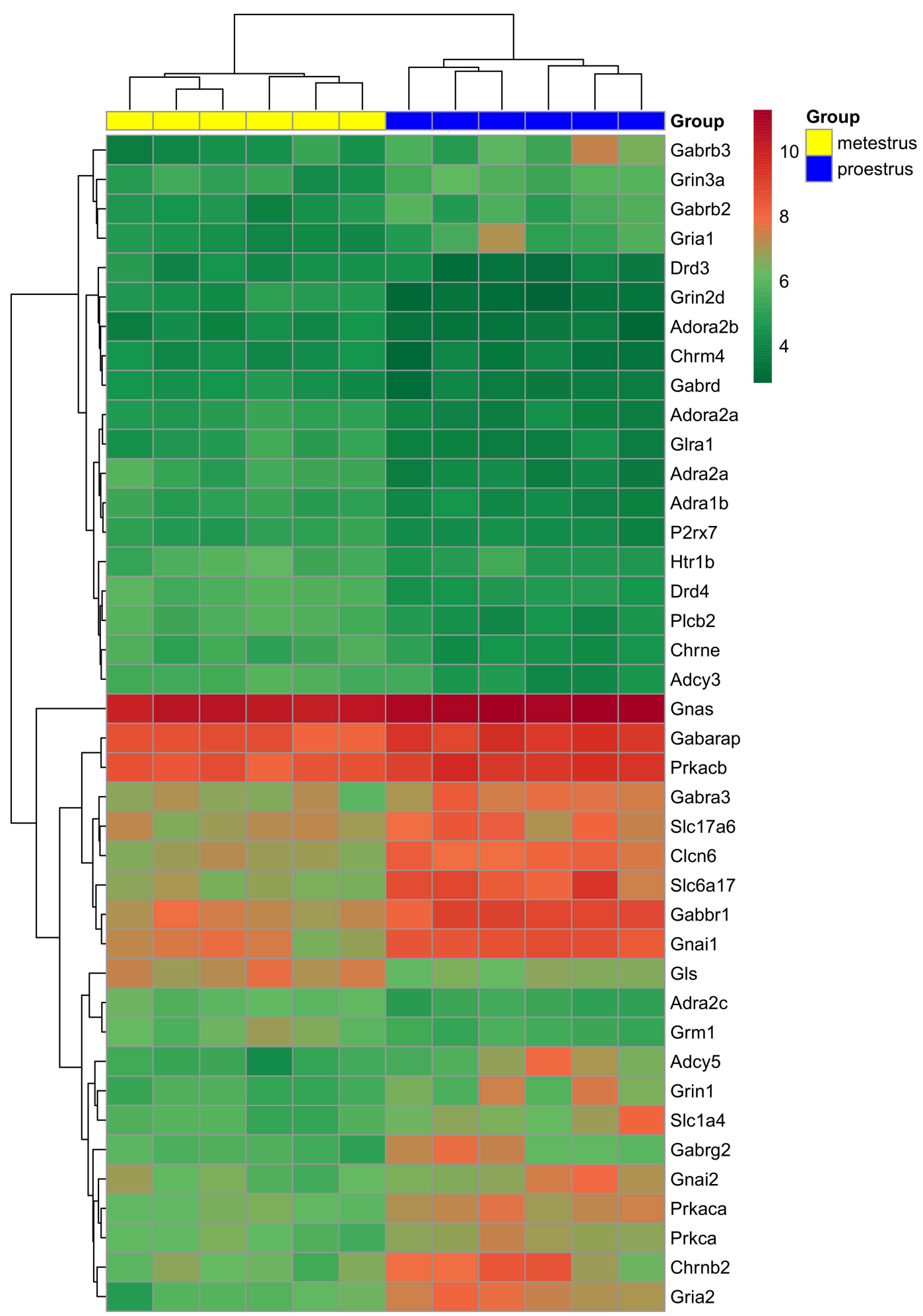

FIGURE 1 | Hierarchical clustering of genes and microarray experiments. Expression levels of the genes involved neurotransmitter signaling (see also Table 1) are visualized on a heat map. The rows represent differentially expressed probe sets with corresponding gene symbols on the right. The expression level of each probe is color coded: for decoding, see the color key. The individual samples are shown as columns. The six proestrous and metestrous samples are coded in blue and yellow, respectively. 
TABLE 1 | Differentially expressed genes involved in neurotransmitter signaling of GnRH neurons.

Upregulated genes in proestrus

\begin{tabular}{|c|c|c|c|c|c|}
\hline Affymetrix ID & AE & Symbol & Description & FC & adj $p$-value (FDR) \\
\hline \multicolumn{6}{|c|}{ CHOLINERGIC SIGNALING } \\
\hline 1420744_PM_at & 123.0 & Chrnb2 & cholinergic receptor, nicotinic, beta polypeptide 2 (neuronal) & 2.65 & 2.17E-02 \\
\hline \multicolumn{6}{|c|}{ GABAergic SIGNALING } \\
\hline 1455021_PM_at & 269.3 & Gabbr1 & gamma-aminobutyric acid (GABA) B receptor, 1 & 2.80 & 5.95E-04 \\
\hline 1421263_PM_at & 145.2 & Gabra3 & gamma-aminobutyric acid (GABA) A receptor, subunit alpha 3 & 1.90 & 1.77E-02 \\
\hline 1418177_PM_at & 76.6 & Gabrg2 & gamma-aminobutyric acid (GABA) A receptor, subunit gamma 2 & 2.20 & 2.96E-02 \\
\hline 1416937_PM_at & 481.4 & Gabarap & gamma-aminobutyric acid receptor associated protein & 1.82 & 4.36E-03 \\
\hline \multicolumn{6}{|c|}{ G-PROTEINS AND DOWNSTREAM EFFECTORS } \\
\hline 1427510_PM_at & 241.6 & Gnai1 & guanine nucleotide binding protein (G protein), alpha inhibiting 1 & 2.59 & 1.49E-03 \\
\hline 1435652_PM_a_at & 98.2 & Gnai2 & guanine nucleotide binding protein (G protein), alpha inhibiting 2 & 1.88 & 4.71E-02 \\
\hline 1420611_PM_at & 496.7 & Prkacb & protein kinase, cAMP dependent, catalytic, beta & 1.86 & $1.22 \mathrm{E}-03$ \\
\hline 1427562_PM_a_at & 87.5 & Prkca & protein kinase $\mathrm{C}$, alpha & 1.78 & 7.51E-03 \\
\hline \multicolumn{6}{|c|}{ GLUTAMATERGIC SIGNALING } \\
\hline 1421970_PM_a_at & 99.7 & Gria2 & glutamate receptor, ionotropic, AMPA2 (alpha 2) & 3.13 & 1.35E-03 \\
\hline 1435239_PM_at & 30.6 & Gria1 & glutamate receptor, ionotropic, AMPA1 (alpha 1) & 2.36 & 2.84E-02 \\
\hline 1437968_PM_at & 65.0 & Grin1 & glutamate receptor, ionotropic, NMDA1 (zeta 1) & 2.24 & 2.73E-02 \\
\hline 1438866_PM_at & 39.9 & Grin3a & glutamate receptor ionotropic, NMDA3A & 1.80 & 2.11E-02 \\
\hline \multicolumn{6}{|c|}{ SOLUTE CARRIER FAMILY } \\
\hline 1418610_PM_at & 173.0 & Slc17a6 & solute carrier family 17 (sodium-dependent inorganic phosphate cotransporter), member 6 & 1.77 & 1.46E-02 \\
\hline 1423549_PM_at & 74.0 & Slc1a4 & solute carrier family 1 (glutamate/neutral amino acid transporter), member 4 & 2.24 & 1.46E-02 \\
\hline 1436137_PM_at & 189.0 & Slc6a17 & solute carrier family 6 (neurotransmitter transporter), member 17 & 3.55 & 1.30E-03 \\
\hline
\end{tabular}

\section{Downregulated genes in proestrus}

\begin{tabular}{|c|c|c|c|c|c|}
\hline \multicolumn{6}{|c|}{ ADENOSINERGIC SIGNALING } \\
\hline 1427519_PM_at & 21.7 & Adora2a & adenosine A2a receptor & 0.50 & 7.47E-04 \\
\hline 1450214_PM_at & 13.7 & Adora2b & adenosine $\mathrm{A} 2 \mathrm{~b}$ receptor & 0.59 & 7.64E-03 \\
\hline \multicolumn{6}{|c|}{ ADRENERGIC SIGNALING } \\
\hline 1422183_PM_a_at & 24.0 & Adra1b & adrenergic receptor, alpha $1 \mathrm{~b}$ & 0.49 & $5.18 \mathrm{E}-04$ \\
\hline 1423022_PM_at & 25.0 & Adra2a & adrenergic receptor, alpha $2 \mathrm{a}$ & 0.37 & 5.07E-04 \\
\hline 1422335_PM_at & 50.0 & Adra2c & adrenergic receptor, alpha 2c & 0.56 & $1.22 \mathrm{E}-03$ \\
\hline \multicolumn{6}{|c|}{ CHOLINERGIC SIGNALING } \\
\hline 1420560_PM_at & 30.3 & Chrne & cholinergic receptor, nicotinic, epsilon polypeptide & 0.52 & 4.98E-03 \\
\hline \multicolumn{6}{|c|}{ DOPAMINERGIC SIGNALING } \\
\hline 1422278_PM_at & 16.0 & Drd3 & dopamine receptor D3 & 0.60 & 4.99E-02 \\
\hline 1422829_PM_at & 36.7 & Drd4 & dopamine receptor D4 & 0.45 & 8.28E-05 \\
\hline \multicolumn{6}{|c|}{ GABAergic SIGNALING } \\
\hline 1452481_PM_at & 32.8 & Plcb2 & phospholipase C, beta 2 & 0.42 & 3.99E-04 \\
\hline
\end{tabular}


Downregulated genes in proestrus

\begin{tabular}{|c|c|c|c|c|c|}
\hline Affymetrix ID & AE & Symbol & Description & FC & adj $p$-value (FDR) \\
\hline \multicolumn{6}{|c|}{ GLUTAMATERGIC SIGNALING } \\
\hline 1438827_PM_at & 118.3 & Gls & Glutaminase & 0.56 & 4.53E-03 \\
\hline 1425700_PM_at & 57.6 & Grm1 & glutamate receptor, metabotropic 1 & 0.53 & $5.78 \mathrm{E}-03$ \\
\hline 1421393_PM_at & 15.1 & Grin2d & glutamate receptor, ionotropic, NMDA2D (epsilon 4) & 0.37 & 1.49E-04 \\
\hline \multicolumn{6}{|c|}{ SEROTONERGIC SIGNALING } \\
\hline 1422218_PM_at & 24.0 & P2rx7 & purinergic receptor P2X, ligand-gated ion channel, 7 & 0.59 & $2.20 \mathrm{E}-03$ \\
\hline \multicolumn{6}{|l|}{ OTHERS } \\
\hline 1422277_PM_at & 20.6 & Glra1 & glycine receptor, alpha 1 subunit & 0.49 & $2.76 \mathrm{E}-03$ \\
\hline
\end{tabular}

The list of differentially expressed genes (DEGs) with false discovery rate (FDR) value $<0.05$ was screened for genes that are involved in neurotransmitter signaling, i.e., receptor subunits, enzymes, G-proteins. DEGs of the major neurotransmitter/neuromodulatory systems are listed here: GABAergic, glutamatergic, dopaminergic, adrenergic, serotonergic, cholinergic, purinergic, and adenosinergic systems. FC values indicate the changes of expression in the proestrous vs. metestrous GnRH neurons. AE, average expression values at probeset level.

Gabrb1, Gabrb2, Gabrb3, Gabrg2; down-regulated: Gabrd). The GABA-B receptor 1 (Gabbr1) and several downstream G-proteins (Gnai1, Gnai2, Gnb2, Gng2, Gng3, Gnao1), and cAMPdependent protein kinase C (Prkaca, Prkacb) were up-regulated. The adenylate cyclases involved in the GABA-B signaling were either upregulated $(A d c y 2, A d c y 5)$ or downregulated $(A d c y 3, A d c y 4)$ in proestrus (Figure 3A and Supplementary Table 2).

\section{Cholinergic Signaling}

Changes in gene expression levels of the "cholinergic synapse" (pGFdr $=3.80 \mathrm{E}-02)$ indicate an activation $(\mathrm{tA}=11.92$, Table 2) of this KEGG pathway that involved 29 differentially expressed genes (Figure 2B). Nicotinic (Chrne) and muscarinic (Chrm4) cholinergic receptors were down-regulated in $\mathrm{GnRH}$ neurons, with the exception of the nicotinic acetylcholine receptor subunit Chrnb2 (Table 1) which was up-regulated at proestrus. Upregulation of genes in the signaling cascade (Gnai1, Gnai2, Gnb2, Gng2, Gng3, Gnao1, Prkaca, and Prkacb) was observed. The Gna11 and Gnaq subunits that form the Gq alpha complex and activate the phospholipase C beta 2 (Plcb2), were up-regulated, whereas Plcb2 was down-regulated in proestrus. The expression level of the calcium/calmodulindependent protein kinase II alpha, beta and gamma (Camk2a, Camk2g, and Camk2b, respectively) and Fos were significantly higher in proestrus (Figure 3B, Supplementary Figure 4 and Supplementary Table 2).

\section{Dopaminergic Signaling}

Dopaminergic signaling pathway (pGFdr $=3.55 \mathrm{E}-02)$ in $\mathrm{GnRH}$ neurons was stated as inhibited $(\mathrm{tA}=-0.18)$ in proestrus revealed by SPIA (Table 2, Figure 3C, and Supplementary Figures 4,5). According to the microarray data, the expression level of the dopaminergic receptor D3 and D4 (Drd3 and Drd4) was significantly decreased as compared to metestrus. Up-regulation of G-proteins (Gnai1, Gnai2, Gnb2, Gng2, Gng3, and Gnao1) and protein kinases (Prkaca and Prkacb) have been already shown at the GABAergic and cholinergic signaling cascades. Adenylate cyclase (Adcy5), inhibited by the upstream G-protein complex, was up-regulated, whereas $P l b c 2$ activated at protein level, was down-regulated. The glutamatergic pathway interferes with the dopaminergic signals: the upregulation of AMPA 1 and 2 (Gria1, Gria2) receptors are linked with the upregulation of the Akt/Gsk3 pathway: kinesin family members Kif5c, Kif5b, and Kif5 indirectly, whereas $A k t 3$, from the dopaminergic side, directly inhibits $G s k 3 a$ and Gsk3b.

\section{Neurotransmitter Receptor Binding and Postsynaptic Signaling}

An activated pathway ( $\mathrm{tA}=250.53$ ) called "Neurotransmitter Receptor Binding and Downstream Transmission in the Postsynaptic Cell" (pGFdr $=3.37 \mathrm{E}-06$ ) was identified in the proestrous GnRH neurons (Table 2 and Figure 4). The majority of the pathway is built up by hierarchically numbered clustershighly interconnected regions-as defined by the MCODE Cytoscape plugin. Within the top relevant cluster \#1 significant enrichment of genes in the "ionotropic glutamate receptor complex" (Gria1, Dlg4; GO; FDR = 5.37E-16) and "calmodulin binding” (Camk2a, Camk2b, Camk2g; GO; FDR = 2.71E-06) terms were found. Genes of the cluster \#2 were elements of "NMDA receptor complex" (GO; 6.23E-12), in which Grin1 and Rasgrf1 were up-, whereas Grin $2 d$ was downregulated. In cluster \#3, which is specific for "acetylcholine-gate channel complex" (GO, FDR = 1.16E-23), acetylcholine receptor subunits (Chrne, Chrnb3, Chrna6) were downregulated. Cluster \#4 is functionally connected with several other sub-networks (glutamatergic, cholinergic, and GABAergic receptors). This cluster is built up by heterotrimeric G-proteins that involves increased mRNA levels of alpha subunit Gnai1, Gnai2, Gnai3, Gnal, and adenylate cyclases of which Adcy3 and Adcy4 are downregulated, Adcy5 is upregulated. Cluster \#5 and \#6 are parts of the GABA-B and GABA-A receptor complexes, 
A

\begin{tabular}{|c|c|c|c|c|c|c|}
\hline \multirow{2}{*}{ Taqman ID } & \multirow{2}{*}{ Gene symbol } & \multirow{2}{*}{ Description } & \multicolumn{2}{|c|}{ Real-time PCR } & \multicolumn{2}{|c|}{ Microarray } \\
\hline & & & $\mathrm{RQ}$ & $p$ value & FC & FDR \\
\hline Mm00444578_m1 & Gabbr1 & gamma-aminobutyric acid (GABA) B receptor, 1 & 1.54 & 0.01 & 2.19 & 1.65E-03 \\
\hline Mm00433473_m1 & Gabrb3 & gamma-aminobutyric acid (GABA) A receptor, subunit beta 3 & 2.25 & 0.10 & 3.05 & 1.53E-02 \\
\hline Mm00515323_m1 & Chrnb2 & cholinergic receptor, nicotinic, beta polypeptide 2 (neuronal) & 2.29 & 0.10 & 2.65 & 2.17E-02 \\
\hline Mm00433822_m1 & Grin2d & glutamate receptor, ionotropic, NMDA2D (epsilon 4) & 0.46 & 0.14 & 0.37 & 1.49E-04 \\
\hline Mm00433790_m1 & Grin1 & glutamate receptor, ionotropic, NMDA1 (zeta 1) & 2.20 & 0.18 & 2.24 & 2.73E-02 \\
\hline Mm00433467_m1 & Gabrb2 & gamma-aminobutyric acid (GABA) A receptor, subunit beta 2 & 3.64 & 0.28 & 1.97 & $1.36 \mathrm{E}-02$ \\
\hline Mm01294271_m1 & Gabra3 & gamma-aminobutyric acid (GABA) A receptor, subunit alpha 3 & 1.30 & 0.35 & 1.90 & 1.77E-02 \\
\hline Mm00442822_m1 & Gria2 & glutamate receptor, ionotropic, AMPA2 (alpha 2) & 0.92 & 0.38 & 3.13 & 1.35E-03 \\
\hline
\end{tabular}

B

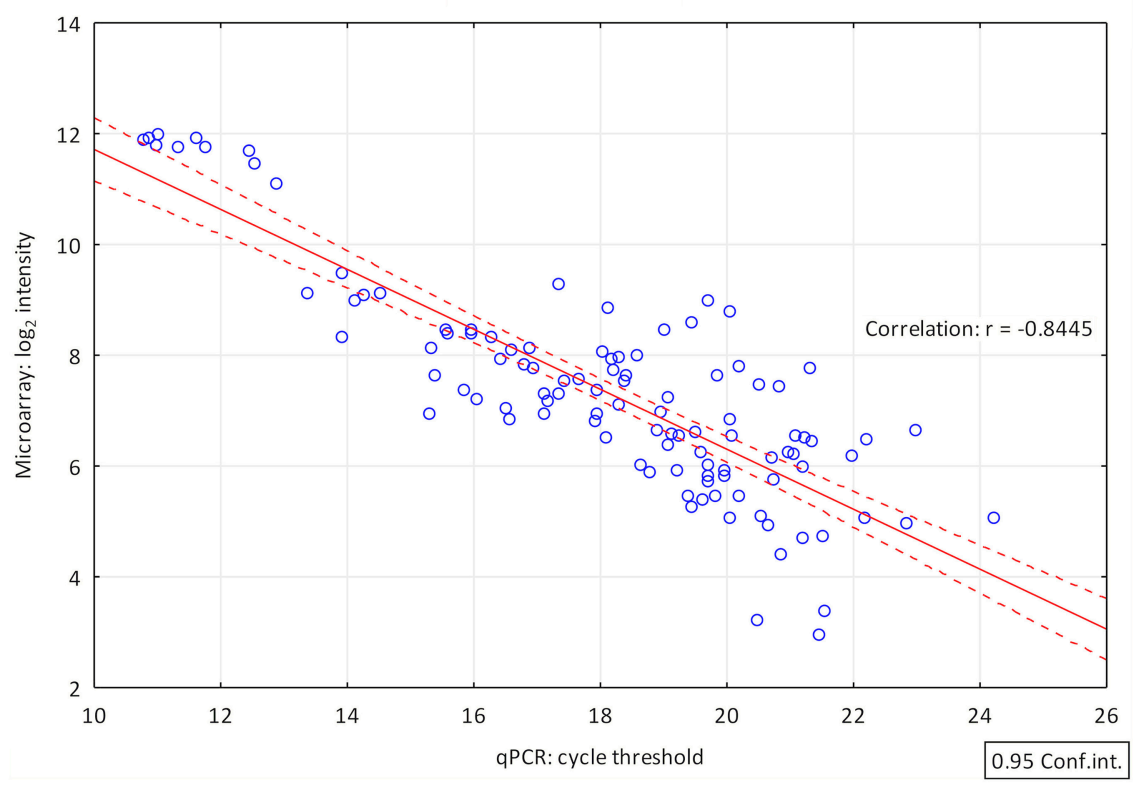

FIGURE 2 | Validation of differential gene expression data by quantitative real-time PCR. (A) List of genes (FC > 1.6; FDR < 0.05) selected for validation of their differential expression by GPCR. The qPCR confirmed the differential expression of 8 genes. RQ, relative quantity (B) The correlation coefficient (Pearson's $r=$ -0.8445 ) indicates the quantitative correlation between the $\log _{2}$ transformed and normalized spot intensity values of microarray hybridizations and the cycle threshold (Ct) value of the $\mathrm{qPCR}$ investigations. X-axis, cycle threshold value; Y-axis, normalized microarray expression values.

TABLE 2 | Significant pathways involved in neurotransmitter signaling identified by Signaling Pathway Impact Analysis (SPIA).

\begin{tabular}{|c|c|c|c|c|c|c|c|c|c|c|}
\hline Database & Pathway & pSize & NDE & pNDE & tA & pPERT & pG & pGFdr & pGFWER & Status \\
\hline REACTOME & $\begin{array}{l}\text { Neurotransmitter Receptor Binding And } \\
\text { Downstream Transmission In The } \\
\text { Postsynaptic Cell }\end{array}$ & 109 & 41 & 9.11E-05 & 250.53 & 5.00E-06 & 1.03E-08 & 3.37E-06 & 3.37E-06 & Activated \\
\hline REACTOME & $\begin{array}{l}\text { Activation of NMDA receptor upon } \\
\text { glutamate binding and postsynaptic } \\
\text { events }\end{array}$ & 26 & 10 & 3.72E-02 & 50.73 & $5.00 \mathrm{E}-06$ & 3.07E-06 & 5.05E-04 & $1.01 \mathrm{E}-03$ & Activated \\
\hline KEGG & Cholinergic synapse & 91 & 29 & 1.40E-02 & 11.92 & 7.70E-02 & 8.45E-03 & 3.80E-02 & 9.97E-01 & Activated \\
\hline
\end{tabular}

Out of significant pathways (pGFdr < 0.05) the neurotransmission signaling-related pathways are shown in the table. Legend to figure: pSize, the number of genes in the pathway; NDE, number of differentially expressed genes in the pathway; PNDE, hypergeometric probability of observing NDE differentially expressed genes in the pathway by chance; $t A$, observed value of the perturbation score; pPERT, bootstrap probability associated to tA; $p G$, combined probability of pNDE and pPERT; pGFDR, adjusted pG using False Discovery Rate correction; pGFWER, adjusted pG using Family Wise Error Rate (Bonferroni); STATUS, Inhibition/Activation according to the negative/positive sign of tA. 
respectively, where Gabbr1, Gabrb1, Gabrb2, and Gabrb3 genes are upregulated.

\section{DISCUSSION}

Fast synaptic neurotransmission is mediated by postsynaptic ionotropic receptors (Greengard, 2001). GABA and glutamate, the two main neurotransmitter systems, play a fundamental role in the regulation of $\mathrm{GnRH}$ neurons (Nikolarakis et al., 1988; Donoso et al., 1992; Ottem et al., 2002; Iremonger et al., 2010; Herbison and Moenter, 2011) and the control of ovulation (Christian and Moenter, 2008).

\section{Gabaergic Signaling}

In the previous decades, it was shown that hypothalamic GnRH neurons receive functional GABAergic primary afferent inputs (Leranth et al., 1985; Adler and Crowley, 1986; Herbison and Dyer, 1991; Kimura and Jinnai, 1994; Jung et al., 1998; Sim et al., 2000; DeFazio et al., 2002; Temple and Wray, 2005; Zhang et al., 2009). The estrous cycle is characterized by profound changes in GABA transmission to GnRH neurons (Herbison, 1997): prior the LH surge the mRNA level of the GABA synthetizing enzyme GAD67 is significantly reduced (Herbison et al., 1992) which exhibits E2-dependent temporal pattern in the territory of the AVPV (Curran-Rauhut and Petersen, 2002). The release of GABA also falls significantly prior to and during the time of estrogen-induced LH surges (Jarry et al., 1992; Tin-Tin-WinShwe et al., 2004). This drop of GABA level before the surge seems essential for the positive feedback (Herbison and Dyer, 1991; Kimura and Jinnai, 1994).

Expression of the $\alpha 1-3, \alpha 5, \beta 1-3$, and $\gamma 2$ subunits of the $\mathrm{GABA}_{\mathrm{A}}$ receptor were detected in the GnRH neurons of adult female mice earlier (Sim et al., 2000). We found an increased mRNA expression level of the $\alpha 1, \beta 1-3$, and $\gamma 2$ subunits and in the proestrous female. Although a GnRH neuron-specific $\gamma 2$ knock-out mice exhibited normal fertility (Lee et al., 2010), higher level of this subunit can increase the conductance and sensitivity of the $\mathrm{GABA}_{\mathrm{A}}$ receptors (Brickley et al., 1999). The increased mRNA level of the $G A B A_{B}$ receptor 1 and that of several $\mathrm{GABA}_{\mathrm{A}}$ subunits might also indicate the upregulation of these receptors in response of the dropping GABA level in proestrus. However, the observed negative value of the perturbation score $(\mathrm{tA}=-4.55)$ indicates a repressed status of the complete GABAergic synapse pathway in GnRH neurons, probably due to downregulation of genes (effector proteins i.e., Adcy4, Adcy3, Plcb2), downstream to the GABA receptors in the signaling pathway. Recent functional data support the view that net GABA effects might be determined by the balance of the excitatory $\mathrm{GABA}_{\mathrm{A}}$ (Herbison and Moenter, 2011) and inhibitory $\mathrm{GABA}_{B}$ (Zhang et al., 2009; Liu et al., 2011) receptor-mediated tones on GnRH neurons, even in vivo (Constantin et al., 2013). We showed higher expression of both type of the GABA receptors and a repressed status of the GABAergic pathway suggesting an increased sensitivity for the ligand and inhibited signaling cascade that might play a role in the facilitation of the GnRH surge.

\section{Glutamatergic Signaling}

GnRH neurons express ionotropic AMPA ( $\alpha$-amino-3-hydroxy5-methyl-4-isoxazolepropionic acid) and NMDA (N-methyl-Daspartate) receptors (Gore et al., 1996; Spergel et al., 1999; Ottem et al., 2002) and their antagonists block the LH surge (López et al., 1990, 1992; Brann and Mahesh, 1991; Ping et al., 1997) indicating a prominent role of glutamate in the positive feedback regulation. At the time of the GnRH/LH surge, the number of contacts that express both glutamate and GABA transporters (Ottem et al., 2004), as well as the level of glutamate increases in the neighborhood of the GnRH cell bodies (Ping et al., 1994; Jarry et al., 1995). The expression of AMPA receptors changes at the level of the somata in steroid-induced LH surge model of young female rats, although, very few (1\%) GnRH neurons cosynthetize AMPA receptors and Fos in the morning of proestrus. In contrast, the increase in the number of Grial/Fos positive (25\%) and Gria2/Fos positive (71\%) GnRH neurons coincides with the increase and peak of LH (Bailey et al., 2006). In concert with these data, we found that expression of the AMPA1 and AMPA2 receptor subunits (Gria1 and Gria2, respectively) increased by the time of LH surge. Though the percentage of NMDAR1-immunopositive GnRH neurons does not change in the mouse (Adjan et al., 2008), we found that the expression level of NMDA subunits Grin1 and Grin3a increased significantly in proestrus. The higher expression level of these receptor subunits and enrichment of genes in the ionotropic glutamate receptor complex suggest an enhanced glutamate receptor signaling in $\mathrm{GnRH}$ neurons during the preovulatory $\mathrm{GnRH} / \mathrm{LH}$ surge.

\section{Cholinergic Signaling}

In the past decades, acetylcholine ( $\mathrm{ACh}$ ) has been shown to exert a stimulatory effect on the release of the GnRH peptide in vitro (Fiorindo and Martini, 1975; Richardson et al., 1982). Cholinergic afferents to hypothalamic GnRH neurons have been detected at both light and electron microscopic levels in the rat (Turi et al., 2008). Studies using perifused hypothalamic and immortalized GnRH (GT1-7) neurons indicated that selective activation of the nicotinic ACh receptor stimulated, in contrast, muscarinic receptor-specific activation inhibited $\mathrm{GnRH}$ release (Krsmanovic et al., 1998). In vivo pharmacological experiments in rats suggested an estrous cycle-dependent stimulation of GnRH release by selective muscarinic antagonists (Koren et al., 1992) induced via the M4 receptor subtype encoded by the Chrm 4 gene. We found a significantly downregulated Chrm 4 expression in proestrus and an upregulated level of Chrnb2. The altered regulation of the two subunits and the diverse action of the nicotinic and muscarinic-type $\mathrm{ACh}$ receptor activation can promote GnRH release and surge in proestrus.

\section{Dopaminergic Signaling}

GnRH neurons receive tyrosine-hydroxylase (TH) positive terminals demonstrated both at light microscopic (Jennes et al., 1983) and ultrastructural levels (Leranth et al., 1988; Chen et al., 1989; Horvath et al., 1993). Dual phenotype kisspeptinTH positive fibers of AVPV origin apposed to the somata of $\mathrm{GnRH}$ neurons can be one of the sources of these dopaminergic 

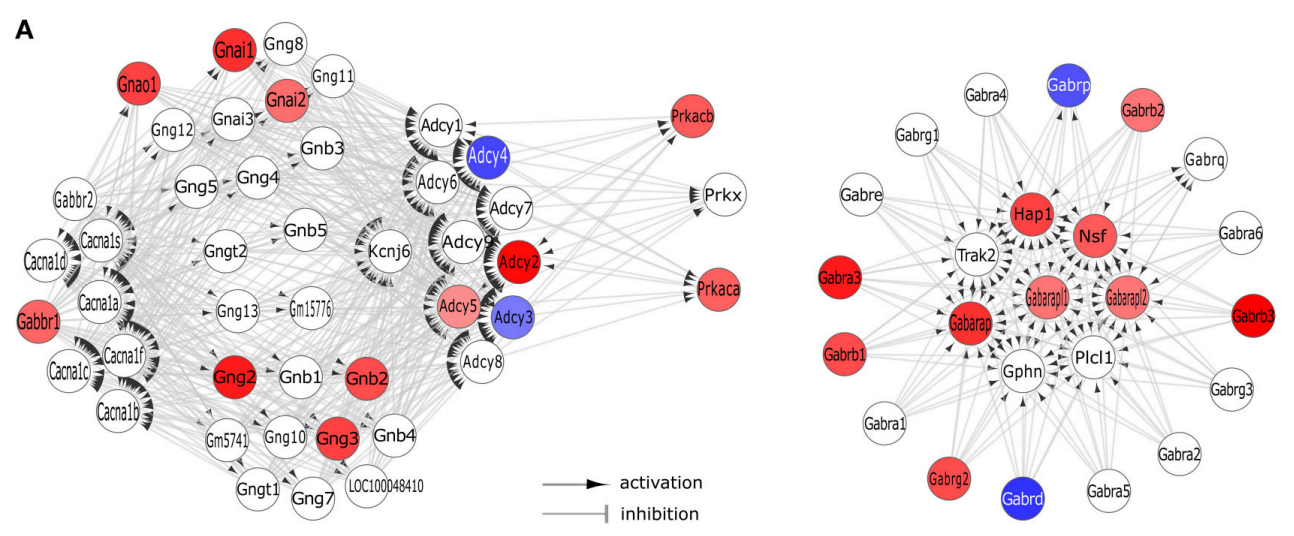

B

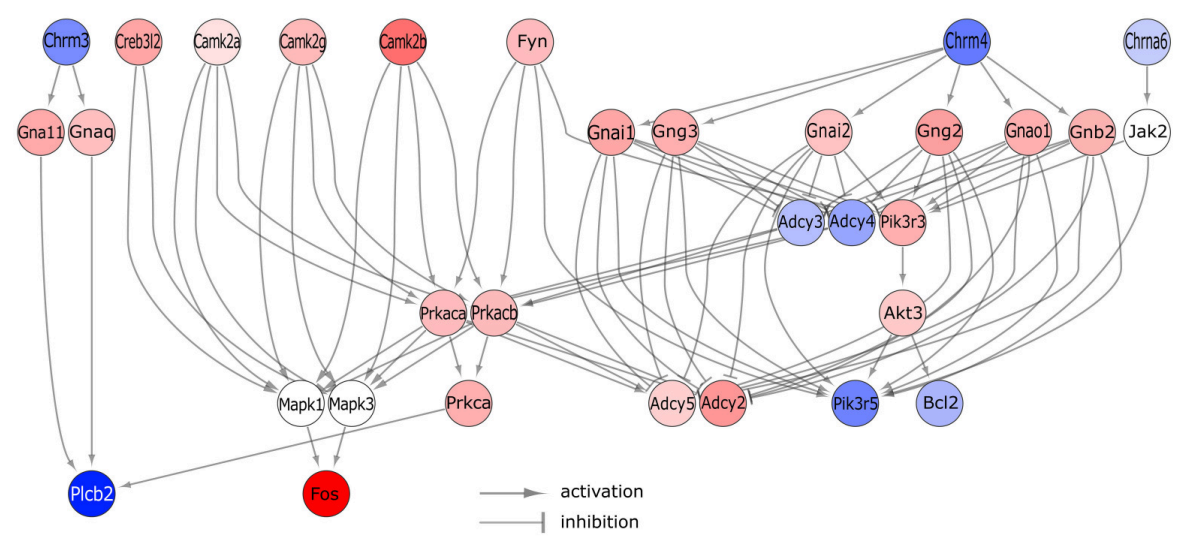

C

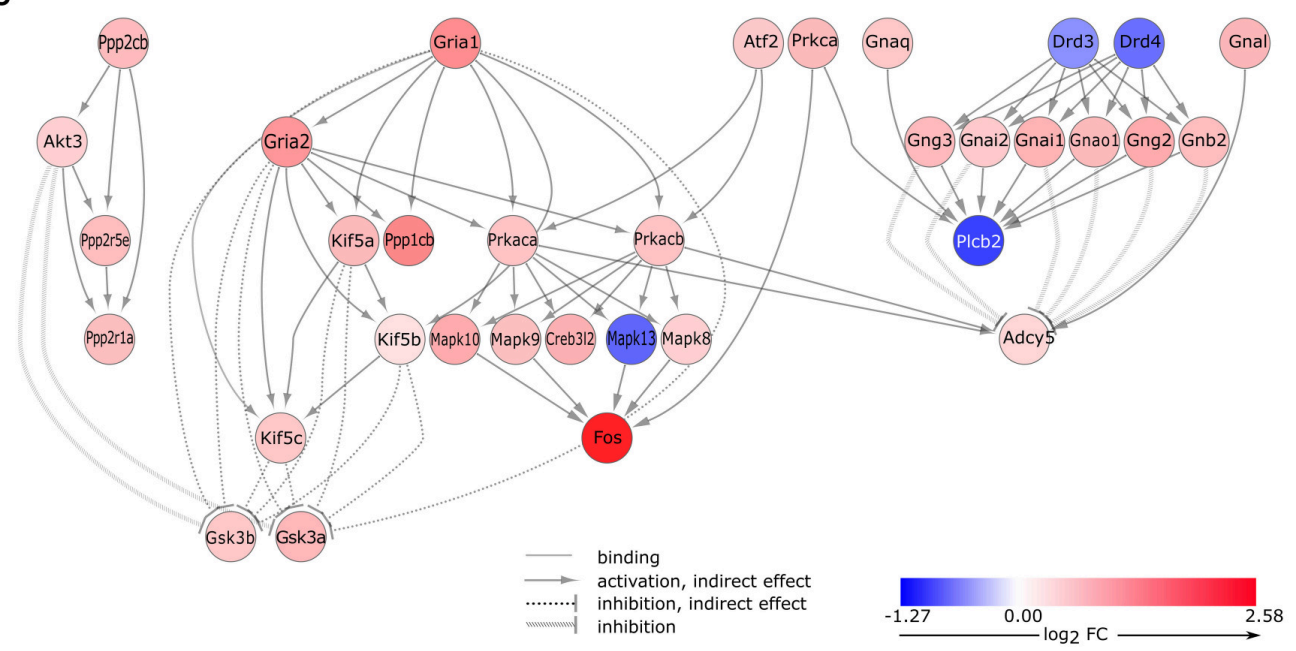

FIGURE 3 | Gene expression changes in neurotransmitter signaling pathways. (A) GABA-ergic synapse pathway. Signaling Pathway Impact Analysis (SPIA) of the microarray data revealed significant enrichment of differentially expressed genes (DEGs) in the "GABAergic synapse" pathway (Bonferroni $p=0.005)$. Nodes and edges of the graph represent genes and their relations, respectively. Colored nodes indicate DEGs with color proportional to log2 fold change values. White node are genes that are not expressed differentially. (B) DEGs of the cholinergic synapse pathway. Gene expression data analysis by SPIA revealed differentially expressed genes that are involved in the "cholinergic signaling" pathway (Bonferroni $p=0.038$ ). Interaction of differentially expressed genes are presented here. The complete pathway is shown in Supplementary Figure 4. (C) DEGs of the dopaminergic synapse pathway. Microarray data analysis by SPIA showed that a significant number of the differentially expressed genes was enriched in the dopaminergic signaling pathway (Bonferroni $p=0.035$ ). Interaction of differentially expressed genes are presented here; the complete pathway is depicted in Supplementary Figure 5. 


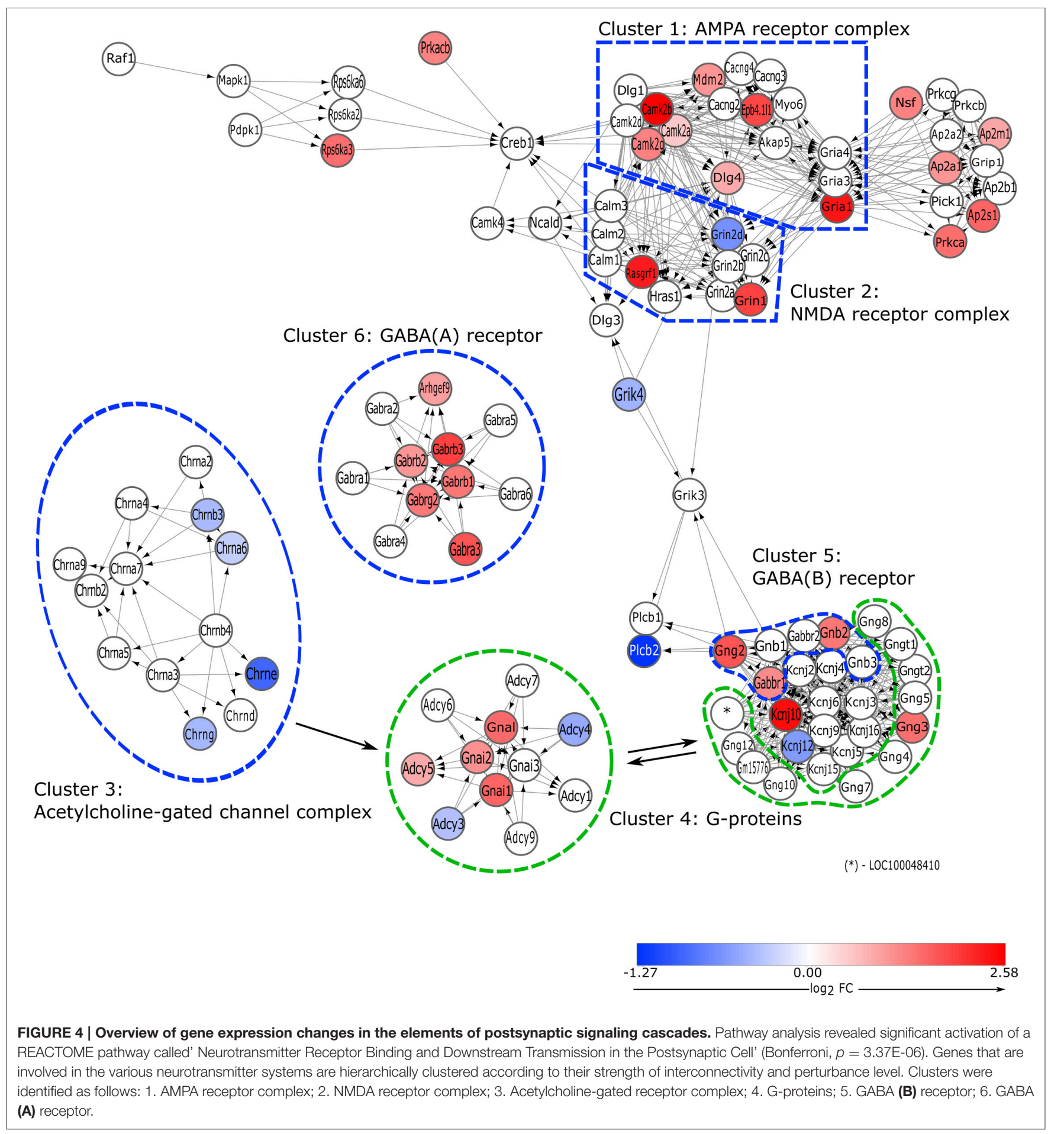

inputs (Clarkson and Herbison, 2011). Dopamine inhibited the firing and AVPV-evoked GABA/glutamate postsynaptic currents in $\sim 50 \%$ of the GnRH neurons in vitro mediated by D1 and D2like receptors in male and female mice (Liu and Herbison, 2013) showing no evidence of an estrous cycle-dependent modulation when diestrous, proestrous, and estrous female mice were compared in the morning period. In the current study, D2-like dopamine receptors encoded by $D r d 3$ and $D r d 4$ genes were found to be down-regulated in proestrous GnRH neurons, suggesting that expression of these genes are affected by the estrous cycle. However, further functional studies are needed to clarify if downregulation in the expression of the D3 and D4 receptor genes can decrease the inhibitory effect of dopamine on the excitability of the GnRH neurons in the late afternoon period of proestrus. 


\section{Adrenergic Signaling}

Numerous studies have supported the view for a long time that norepinephrine (NE) exerts a stimulatory effect on $\mathrm{GnRH}$ release in the presence of $\mathrm{E} 2$ in OVX $+\mathrm{E}$ replacement models (Gallo and Drouva, 1979; Ferris et al., 1984; Wise, 1984). Later, NE was found to suppress the excitability of the GnRH neurons acting through both alpha 1 and beta adrenergic receptors with reduced rate of responsive $\mathrm{GnRH}$ neurons during proestrus, otherwise exerting a similar effect across the estrous cycle (Han and Herbison, 2008). We found that adrenergic receptors Adra1b, Adra2a, and Adra2c are significantly downregulated in proestrus compared to metestrus. The decreased mRNA expression level of these receptors might indicate an attenuated catecholamine sensitivity of GnRH neurons specifically in the late afternoon period; prior to and during LH surge.

\section{Serotonergic Signaling}

Earlier investigations provided evidence that 5-HT neurons project directly to GnRH neurons in rodents (Jennes et al., 1982; Kiss and Halász, 1985; Wada et al., 2006; Campbell and Herbison, 2007) In the mouse, serotonin (5-HT) exerts a biphasic effect on the excitability of GnRH neurons: both inhibitory and excitatory responses have been demonstrated, mediated by activation of 5HT1A and 5-HT2A receptors, respectively (Bhattarai et al., 2014). The serotonergic input to GnRH neurons showed an estrous cycle-dependent regulation in the adult female mouse: during proestrus, the serotonergic inhibition was reduced, accompanied by the absence of the biphasic responses. The 5 - HT1B receptor also mediates inhibitory neurotransmission (Mathur et al., 2011; Huang et al., 2013) in the CNS. Although the function of the 5 -HT1B receptor was not investigated in GnRH neurons to date, we found that it was down-regulated in proestrous $\mathrm{GnRH}$ neurons. Compared to other stages of the estrous cycle, 5HT1 receptor expression is decreased up to $40 \%$ in the basal forebrain during proestrus (Biegon et al., 1980) when peaking level of E2 significantly down-regulates 5-HT receptors (Biegon and McEwen, 1982). The current study further supports that a suppression of the inhibitory 5-HT tone takes place in $\mathrm{GnRH}$ neurons in proestrus.

\section{Purinergic Signaling P2X Receptors}

P2X receptors are trimeric, ligand-gated cation channels activated upon binding of extracellular ATP. They are highly permeable to $\mathrm{Ca}^{2+}$ and expressed in diverse organs including the brain (Soto et al., 1996; Burnstock, 2013). Purinergic signaling plays a fundamental role in the regulation of hypothalamopituitary functions (Stojilkovic, 2009). Expression of P2X2 and P2X4 has been confirmed in GnRH neurons in olfactory placode cultures (Terasawa et al., 2005) where application of ATP helps to synchronize $\left[\mathrm{Ca}^{2+}\right]_{\mathrm{i}}$ oscillations. Furthermore, P2X5 and P2X6 receptors are also expressed in $\mathrm{GnRH}$ neurons of mice as revealed by double-labeling immunofluorescence ( $\mathrm{Fu}$ et al., 2009). Interestingly, though the presence of P2X7 receptor has not been confirmed in GnRH neurons to date, the mRNA level of $P 2 x r 7$ is significantly down-regulated in proestrous $\mathrm{GnRH}$ neurons. A possible explanation of this phenomenon may be the E2-dependent regulation of P2X7R expression during the estrous cycle. Data from literature indicate that treatment with $\mathrm{E} 2$ decreases the expression of $\mathrm{P} 2 \mathrm{X} 7$ receptor both in vitro (Cario-Toumaniantz et al., 1998) and in vivo (Xu et al., 2016).

\section{P1 Receptors}

The adenosine receptor $2 \mathrm{~A}$ and $2 \mathrm{~B}$ receptors are members of the $\mathrm{G}$ protein-coupled receptor (GPCR) family. The A2 adenosine receptors are coupled to $G_{s}$ and $G_{\text {olf }}$ family of $G$ proteins stimulating adenylate cyclase activity to increase the intracellular cAMP level (Schwindinger et al., 2010). Expression of Adora2b has been shown in hypothalamic GnRH neurons (Todman et al., 2005). In this study we found significant down-regulation of the Adora $2 a$ and Adora $2 b$ transcripts in proestrous $\mathrm{GnRH}$ neurons. The role and significance of the regulation of adenosine receptor 2 are unknown at present, they may be linked to the maintenance of intracellular cAMP levels along the estrous cycle.

\section{Methodological Considerations Sampling by LCM}

LCM is among the best approaches available for cell-type-specific microarray gene expression profiling (Lin et al., 2007; Okaty et al., 2011; Demarest et al., 2012). This methodology helps to preserve the integrity of the $\mathrm{GnRH}$ transcriptome and ensures the systematic sampling of the hypothalamic GnRH neurons. Our strategy aimed to minimize the extent of contamination from surrounding cells was as follows: (1) brain sections were cut at $7 \mu \mathrm{m}$ thickness; (2) during microdissection, the cutting laser were directed strictly along the perikaryon of the GnRHGFP neurons. While it is not possible to eliminate contamination during sample preparation completely, careful implementation of the steps above results in highly enriched mRNAs isolated from GnRH neurons.

\section{Linearity of the RNA Amplification}

In this work we implemented a relatively new approach for gene expression profiling validated and published earlier (GonzalezRoca et al., 2010) showing that "pico profiling" allows an accurate measure of transcript levels from populations as low as 10 cells with insignificant number of false positive or negative hits, using a commercially available TransPlex WTA2 kit from Sigma-Aldrich. Importantly, at the reverse transcription step the quasi-random $3^{\prime}$ and universal $5^{\prime}$ primers resulted in DNA fragments flanked by universal end sequences to ensure the linear amplification of the expressed genes without $3^{\prime}$ and $5^{\prime}$ bias.

\section{Validation of the Data}

High throughput gene expression analysis of GnRH neurons across the estrous cycle was performed for the first time in the present study. A previous study has addressed ion channel expression and $\mathrm{E} 2$ regulations in $\mathrm{GnRH}$ neurons during negative and positive feedback (Bosch et al., 2013). They showed that E2 treatment up-regulates voltage-gated calcium channel (VGCC) Cav1.3, Cav2.2, and Cav2.3 mRNAs in GnRH neurons. In consistence with their results regarding the expressional changes in the positive feedback period, we have also found a significant increase in the expression of the Cav 2.2, the voltage-dependent 
N-type calcium channel alpha $1 \mathrm{~B}$ subunit encoded by Cacnalb gene (FC 1.7; $p_{\text {adj }}<0.01$ ) in proestrus whereas the increase in mRNA expression the Cav1.3 [Cacnald] and Cav2.3 [Cacnale] subunits was not significant. This discrepancy may be due to the different experimental paradigm: Bosch et al. used ex-vivo sorted GnRH neurons from OVX mice primed with E2 dose followed by a surge-inducing E2 dose, whereas in the current study naturally cycling intact mice were used.

\section{Correlation of mRNA and Protein Abundances}

In this study, differential expression of genes was investigated as alterations in the mRNA abundances. In general, changes of the protein levels should not be well correlated with that of the mRNA levels due to many factors that influence the expression of proteins (ribosomal density, protein half-life, etc.) and the experimental error and noise (Maier et al., 2009; Vogel and Marcotte, 2012). Genome-wide correlations between mRNA and protein expression levels are usually weak (de Sousa Abreu et al., 2009). However, the level of mRNAs expressed differentially significantly correlate better with their proteins compared to genes that are not expressed differentially (Koussounadis et al., 2015) further increasing the confidence of studies applying differential mRNA expression measurements.

\section{CONCLUSION}

We found considerable differences in the expression of genes encoding neurotransmitter receptors and their effectors in downstream signaling cascades by comparison of GnRH neurons obtained from pro- and metestrous mice, respectively. Signaling systems known to facilitate the $\mathrm{GnRH}$ surge (glutamatergic, GABA-A receptor-mediated inputs and cholinergic neurotransmission via nicotinic receptors) become activated, while neuronal inputs that exert inhibitory effects on

\section{REFERENCES}

Adjan, V., Centers, A., and Jennes, L. (2008). Expression and activation of Nmethyl-D-aspartate receptor subunit-1 receptor subunits in gonadotrophinreleasing hormone neurones of young and middle-aged mice during the luteinising hormone surge. J. Neuroendocrinol. 20, 1147-1154. doi: 10.1111/j.1365-2826.2008.01775.x

Adler, B. A., and Crowley, W. R. (1986). Evidence for gamma-aminobutyric acid modulation of ovarian hormonal effects on luteinizing hormone secretion and hypothalamic catecholamine activity in the female rat. Endocrinology 118, 91-97. doi: 10.1210/endo-118-1-91

Bailey, J. D., Centers, A., and Jennes, L. (2006). Expression of AMPA receptor subunits (GluR1-GluR4) in gonadotrophin-releasing hormone neurones of young and middle-aged persistently oestrous rats during the steroid-induced luteinising hormone surge. J. Neuroendocrinol. 18, 1-12. doi: 10.1111/j.13652826.2005.01361.x

Bhattarai, J. P., Roa, J., Herbison, A. E., and Han, S. K. (2014). Serotonin acts through 5-HT1 and 5-HT2 receptors to exert biphasic actions on GnRH neuron excitability in the mouse. Endocrinology 155, 513-524. doi: 10.1210/en. 2013-1692

Biegon, A., Bercovitz, H., and Samuel, D. (1980). Serotonin receptor concentration during the estrous cycle of the rat. Brain Res. 187, 221-225. doi: 10.1016/00068993(80)90509-0

Biegon, A., and McEwen, B. S. (1982). Modulation by estradiol of serotonin receptors in brain. J. Neurosci. 2, 199-205.
GnRH release (dopaminergic, serotonergic, adrenergic systems) seem to be negatively regulated at the level of transcripts in proestrus. These complex changes in the gene expression of proestrous GnRH neurons may alter diverse intracellular mechanisms that culminate in the preovulatory $\mathrm{GnRH}$ surge.

\section{AUTHOR CONTRIBUTIONS}

CV designed and performed the experiments, analyzed the data and wrote the manuscript. AR executed hybridization and scanning of microarrays. NS carried out the bioinformatical analysis of the microarray data. ZL designed and supervised the project, and wrote the manuscript.

\section{FUNDING}

This work was supported by the Hungarian Scientific Research Fund (OTKA K100722, OTKA 115984).

\section{ACKNOWLEDGMENTS}

Authors wish to express their thanks to Dr. Suzanne M. Moenter (Department of Molecular and Integrative Physiology, University of Michigan) for the transgenic mice used in this study; to Dr. Csaba Fekete (Lendület Laboratory of Integrative Neurobiology, IEM-HAS) for personal communication and advices in LCM methodology.

\section{SUPPLEMENTARY MATERIAL}

The Supplementary Material for this article can be found online at: http://journal.frontiersin.org/article/10.3389/fncel. 2016.00230

Bosch, M. A., Tonsfeldt, K. J., and Rønnekleiv, O. K. (2013). mRNA expression of ion channels in GnRH neurons: subtype-specific regulation by 17beta-estradiol. Mol. Cell. Endocrinol. 367, 85-97. doi: 10.1016/j.mce.2012. 12.021

Brann, D. W., and Mahesh, V. B. (1991). Endogenous excitatory amino acid involvement in the preovulatory and steroid-induced surge of gonadotropins in the female rat. Endocrinology 128, 1541-1547. doi: 10.1210/endo-128-3-1541

Brickley, S. G., Cull-Candy, S. G., and Farrant, M. (1999). Single-channel properties of synaptic and extrasynaptic GABAA receptors suggest differential targeting of receptor subtypes. J. Neurosci. 19, 2960-2973.

Burnstock, G. (2013). Introduction and perspective, historical note. Front. Cell. Neurosci. 7:227. doi: 10.3389/fncel.2013.00227

Byers, S. L., Wiles, M. V., Dunn, S. L., and Taft, R. A. (2012). Mouse estrous cycle identification tool and images. PLOS ONE 7:e35538. doi: 10.1371/journal.pone.0035538

Campbell, R. E. (2007). Defining the gonadotrophin-releasing hormone neuronal network: transgenic approaches to understanding neurocircuitry. J. Neuroendocrinol. 19, 561-573. doi: 10.1111/j.1365-2826.2007. 01561.x

Campbell, R. E., and Herbison, A. E. (2007). Definition of brainstem afferents to gonadotropin-releasing hormone neurons in the mouse using conditional viral tract tracing. Endocrinology 148, 5884-5890. doi: 10.1210/en.2007-0854

Cario-Toumaniantz, C., Loirand, G., Ferrier, L., and Pacaud, P. (1998). Nongenomic inhibition of human P2X7 purinoceptor by 17beta-oestradiol. J. Physiol. 508 (Pt 3), 659-666. 
Carmel, P. W., Araki, S., and Ferin, M. (1976). Pituitary stalk portal blood collection in rhesus monkeys: evidence for pulsatile release of gonadotropinreleasing hormone (GnRH). Endocrinology 99, 243-248. doi: 10.1210/endo-99$1-243$

Chen, W. P., Witkin, J. W., and Silverman, A. J. (1989). Gonadotropin releasing hormone $(\mathrm{GnRH})$ neurons are directly innervated by catecholamine terminals. Synapse 3, 288-290. doi: 10.1002/syn.890030314

Cheong, R. Y., Czieselsky, K., Porteous, R., and Herbison, A. E. (2015). Expression of ESR1 in glutamatergic and GABAergic neurons is essential for normal puberty onset, estrogen feedback, and fertility in female mice. J. Neurosci. 35, 14533-14543. doi: 10.1523/JNEUROSCI.1776-15.2015

Chiu, R., Boyle, W. J., Meek, J., Smeal, T., Hunter, T., and Karin, M. (1988). The c-Fos protein interacts with c-Jun/AP-1 to stimulate transcription of AP-1 responsive genes. Cell 54, 541-552. doi: 10.1016/0092-8674(88)90076-1

Christian, C. A., Glidewell-Kenney, C., Jameson, J. L., and Moenter, S. M. (2008). Classical estrogen receptor alpha signaling mediates negative and positive feedback on gonadotropin-releasing hormone neuron firing. Endocrinology 149, 5328-5334. doi: 10.1210/en.2008-0520

Christian, C. A., Mobley, J. L., and Moenter, S. M. (2005). Diurnal and estradioldependent changes in gonadotropin-releasing hormone neuron firing activity. Proc. Natl. Acad. Sci. U.S.A. 102, 15682-15687. doi: 10.1073/pnas.0504270102

Christian, C. A., and Moenter, S. M. (2008). Critical roles for fast synaptic transmission in mediating estradiol negative and positive feedback in the neural control of ovulation. Endocrinology 149, 5500-5508. doi: 10.1210/en.2008-0453

Christian, C. A., and Moenter, S. M. (2010). The neurobiology of preovulatory and estradiol-induced gonadotropin-releasing hormone surges. Endocr. Rev. 31, 544-577. doi: 10.1210/er.2009-0023

Chu, Z., Andrade, J., Shupnik, M. A., and Moenter, S. M. (2009). Differential regulation of gonadotropin-releasing hormone neuron activity and membrane properties by acutely applied estradiol: dependence on dose and estrogen receptor subtype. J. Neurosci. 29, 5616-5627. doi: 10.1523/JNEUROSCI.035209.2009

Clarkson, J., and Herbison, A. E. (2011). Dual phenotype kisspeptin-dopamine neurones of the rostral periventricular area of the third ventricle project to gonadotrophin-releasing hormone neurones. J. Neuroendocrinol. 23, 293-301. doi: 10.1111/j.1365-2826.2011.02107.x

Constantin, S., Iremonger, K. J., and Herbison, A. E. (2013). In vivo recordings of GnRH neuron firing reveal heterogeneity and dependence upon GABAA receptor signaling. J. Neurosci. 33, 9394-9401. doi: 10.1523/JNEUROSCI.053313.2013

Cora, M. C., Kooistra, L., and Travlos, G. (2015). Vaginal cytology of the laboratory rat and mouse: review and criteria for the staging of the estrous cycle using stained vaginal smears. Toxicol. Pathol. 43, 776-793. doi: $10.1177 / 0192623315570339$

Curran-Rauhut, M. A., and Petersen, S. L. (2002). Regulation of glutamic acid decarboxylase 65 and 67 gene expression by ovarian steroids: identification of two functionally distinct populations of GABA neurones in the preoptic area. J. Neuroendocrinol. 14, 310-317. doi: 10.1046/j.1365-2826.2002.00780.x

DeFazio, R. A., Heger, S., Ojeda, S. R., and Moenter, S. M. (2002). Activation of A-type gamma-aminobutyric acid receptors excites gonadotropin-releasing hormone neurons. Mol. Endocrinol. 16, 2872-2891. doi: 10.1210/me.2002-0163

Demarest, T. G., Murugesan, N., Shrestha, B., and Pachter, J. S. (2012). Rapid expression profiling of brain microvascular endothelial cells by immuno-laser capture microdissection coupled to $\operatorname{TaqMan}((\mathrm{R}))$ low density array. J. Neurosci. Methods 206, 200-204. doi: 10.1016/j.jneumeth.2012.02.023

de Sousa Abreu, R., Penalva, L. O., Marcotte, E. M., and Vogel, C. (2009). Global signatures of protein and mRNA expression levels. Mol. Biosyst. 5, 1512-1526. doi: 10.1039/b908315d

Donoso, A. O., López, F. J., and Negro-Vilar, A. (1992). Cross-talk between excitatory and inhibitory amino acids in the regulation of luteinizing hormonereleasing hormone secretion. Endocrinology 131, 1559-1561.

Farkas, I., Vastagh, C., Sárvári, M., and Liposits, Z. (2013). Ghrelin decreases firing activity of gonadotropin-releasing hormone $(\mathrm{GnRH})$ neurons in an estrous cycle and endocannabinoid signaling dependent manner. PLOS ONE 8:e78178. doi: 10.1371 /journal.pone.0078178

Fekete, C. S., Strutton, P. H., Cagampang, F. R., Hrabovszky, E., Kalló, I., Shughrue, P. J., et al. (1999). Estrogen receptor immunoreactivity is present in the majority of central histaminergic neurons: evidence for a new neuroendocrine pathway associated with luteinizing hormone-releasing hormone-synthesizing neurons in rats and humans. Endocrinology 140, 4335-4341. doi: 10.1210/en.140.9.4335

Ferris, C. F., Pan, J. X., Singer, E. A., Boyd, N. D., Carraway, R. E., and Leeman, S. E. (1984). Stimulation of luteinizing hormone release after stereotaxic microinjection of neurotensin into the medial preoptic area of rats. Neuroendocrinology 38, 145-151. doi: 10.1159/000123882

Finn, P. D., Steiner, R. A., and Clifton, D. K. (1998). Temporal patterns of gonadotropin-releasing hormone $(\mathrm{GnRH}), \mathrm{c}$-fos, and galanin gene expression in $\mathrm{GnRH}$ neurons relative to the luteinizing hormone surge in the rat. $J$. Neurosci. 18, 713-719.

Fiorindo, R. P., and Martini, L. (1975). Evidence for a cholinergic component in the neuroendocrine control of luteinizing hormone (LH) secretion. Neuroendocrinology 18, 322-332. doi: 10.1159/000122413

Fu, J., Yu, Q., Guo, W., He, C., Burnstock, G., and Xiang, Z. (2009). P2X receptors are expressed on neurons containing luteinizing hormone-releasing hormone in the mouse hypothalamus. Neurosci. Lett. 458, 32-36. doi: 10.1016/j.neulet.2009.04.017

Gallo, R. V., and Drouva, S. V. (1979). Effect of intraventricular infusion of catecholamines on luteinizing hormone release in ovariectomized and ovariectomized, steroid-primed rats. Neuroendocrinology 29, 149-162. doi: $10.1159 / 000122917$

Gonzalez-Roca, E., Garcia-Albéniz, X., Rodriguez-Mulero, S., Gomis, R. R., Kornacker, K., and Auer, H. (2010). Accurate expression profiling of very small cell populations. PLoS ONE 5:e14418. doi: 10.1371/journal.pone.0014418

Gore, A. C., and Roberts, J. L. (1997). Regulation of gonadotropin-releasing hormone gene expression in vivo and in vitro. Front. Neuroendocrinol. 18, 209-245. doi: 10.1006/frne.1996.0149

Gore, A. C., Wu, T. J., Rosenberg, J. J., and Roberts, J. L. (1996). Gonadotropinreleasing hormone and NMDA receptor gene expression and colocalization change during puberty in female rats. J. Neurosci. 16, 5281-5289.

Greengard, P. (2001). The neurobiology of slow synaptic transmission. Science 294, 1024-1030. doi: 10.1126/science.294.5544.1024

Han, S. K., and Herbison, A. E. (2008). Norepinephrine suppresses gonadotropinreleasing hormone neuron excitability in the adult mouse. Endocrinology 149, 1129-1135. doi: 10.1210/en.2007-1241

Herbison, A. E. (1997). Estrogen regulation of GABA transmission in rat preoptic area. Brain Res. Bull. 44, 321-326. doi: 10.1016/S0361-9230(97)00210-4

Herbison, A. E. (1998). Multimodal influence of estrogen upon gonadotropin-releasing hormone neurons. Endocr. Rev. 19, 302-330. doi: 10.1210/edrv.19.3.0332

Herbison, A. E., Augood, S. J., and McGowan, E. M. (1992). Expression of glutamic acid decarboxylase messenger RNA in rat medial preoptic area neurones during the oestrous cycle and after ovariectomy. Brain Res. Mol. Brain Res. 14, 310-316. doi: 10.1016/0169-328X(92)90098-V

Herbison, A. E., and Dyer, R. G. (1991). Effect on luteinizing hormone secretion of GABA receptor modulation in the medial preoptic area at the time of proestrous luteinizing hormone surge. Neuroendocrinology 53, 317-320. doi: $10.1159 / 000125735$

Herbison, A. E., and Moenter, S. M. (2011). Depolarising and hyperpolarising actions of $\mathrm{GABA}(\mathrm{A})$ receptor activation on gonadotrophin-releasing hormone neurones: towards an emerging consensus. J. Neuroendocrinol. 23, 557-569. doi: 10.1111/j.1365-2826.2011.02145.x

Horvath, T. L., Naftolin, F., and Leranth, C. (1993). Luteinizing hormone-releasing hormone and gamma-aminobutyric acid neurons in the medial preoptic area are synaptic targets of dopamine axons originating in anterior periventricular areas. J. Neuroendocrinol. 5, 71-79. doi: 10.1111/j.1365-2826.1993.tb00365.x

Hosny, S., and Jennes, L. (1998). Identification of alpha1B adrenergic receptor protein in gonadotropin releasing hormone neurones of the female rat. $J$. Neuroendocrinol. 10, 687-692. doi: 10.1046/j.1365-2826.1998.00256.x

Hrabovszky, E., Shughrue, P. J., Merchenthaler, I., Hajszán, T., Carpenter, C. D., Liposits, Z., et al. (2000). Detection of estrogen receptor-beta messenger ribonucleic acid and 125I-estrogen binding sites in luteinizing hormonereleasing hormone neurons of the rat brain. Endocrinology 141, 3506-3509. doi: 10.1210/endo.141.9.7788

Hrabovszky, E., Steinhauser, A., Barabás, K., Shughrue, P. J., Petersen, S. L., Merchenthaler, I., et al. (2001). Estrogen receptor-beta immunoreactivity in luteinizing hormone-releasing hormone neurons of the rat brain. Endocrinology 142, 3261-3264. doi: 10.1210/endo.142.7.8176 
Huang, C. C., Yeh, C. M., Wu, M. Y., and Hsu, K. S. (2013). A single in vivo cocaine administration impairs 5-HT(1B) receptor-induced long-term depression in the nucleus accumbens. J. Neurochem. 125, 809-821. doi: 10.1111/jnc.12227

Huang da, W., Sherman, B. T., and Lempicki, R. A. (2009a). Bioinformatics enrichment tools: paths toward the comprehensive functional analysis of large gene lists. Nucleic Acids Res. 37, 1-13. doi: 10.1093/nar/gkn923

Huang da, W., Sherman, B. T., and Lempicki, R. A. (2009b). Systematic and integrative analysis of large gene lists using DAVID bioinformatics resources. Nat. Protoc. 4, 44-57. doi: 10.1038/nprot.2008.211

Huber, W., Carey, V. J., Gentleman, R., Anders, S., Carlson, M., Carvalho, B. S., et al. (2015). Orchestrating high-throughput genomic analysis with Bioconductor. Nat. Methods 12, 115-121. doi: 10.1038/nmeth.3252

Iremonger, K. J., Constantin, S., Liu, X., and Herbison, A. E. (2010). Glutamate regulation of GnRH neuron excitability. Brain Res. 1364, 35-43. doi: 10.1016/j.brainres.2010.08.071

Irizarry, R. A., Hobbs, B., Collin, F., Beazer-Barclay, Y. D., Antonellis, K. J., Scherf, U., et al. (2003). Exploration, normalization, and summaries of high density oligonucleotide array probe level data. Biostatistics 4, 249-264. doi: 10.1093/biostatistics/4.2.249

Jarry, H., Hirsch, B., Leonhardt, S., and Wuttke, W. (1992). Amino acid neurotransmitter release in the preoptic area of rats during the positive feedback actions of estradiol on LH release. Neuroendocrinology 56, 133-140. doi: $10.1159 / 000126220$

Jarry, H., Leonhardt, S., Schwarze, T., and Wuttke, W. (1995). Preoptic rather than mediobasal hypothalamic amino acid neurotransmitter release regulates $\mathrm{GnRH}$ secretion during the estrogen-induced LH surge in the ovariectomized rat. Neuroendocrinology 62, 479-486. doi: 10.1159/000127037

Jennes, L., Beckman, W. C., Stumpf, W. E., and Grzanna, R. (1982). Anatomical relationships of serotoninergic and noradrenalinergic projections with the GnRH system in septum and hypothalamus. Exp. Brain Res. 46, 331-338. doi: $10.1007 /$ BF00238628

Jennes, L., Stumpf, W. E., and Tappaz, M. L. (1983). Anatomical relationships of dopaminergic and GABAergic systems with the GnRH-systems in the septohypothalamic area. Immunohistochemical studies. Exp. Brain Res. 50, 91-99. doi: 10.1007/BF00238235

Jung, H., Shannon, E. M., Fritschy, J. M., and Ojeda, S. R. (1998). Several GABAA receptor subunits are expressed in LHRH neurons of juvenile female rats. Brain Res. 780, 218-229. doi: 10.1016/S0006-8993(97)01152-9

Kauffmann, A., Gentleman, R., and Huber, W. (2009). arrayQualityMetrics-a bioconductor package for quality assessment of microarray data. Bioinformatics 25, 415-416. doi: 10.1093/bioinformatics/btn647

Kenealy, B. P., Keen, K. L., Rønnekleiv, O. K., and Terasawa, E. (2011). STX, a novel nonsteroidal estrogenic compound, induces rapid action in primate GnRH neuronal calcium dynamics and peptide release. Endocrinology 152, 3182-3191. doi: 10.1210/en.2011-0097

Khodosevich, K., Inta, D., Seeburg, P. H., and Monyer, H. (2007). Gene expression analysis of in vivo fluorescent cells. PLOS ONE 2:e1151. doi: 10.1371/journal.pone.0001151

Kimura, F., and Jinnai, K. (1994). Bicuculline infusions advance the timing of luteinizing hormone surge in proestrous rats: comparisons with naloxone effects. Horm. Behav. 28, 424-430. doi: 10.1006/hbeh.1994.1039

Kiss, J., and Halász, B. (1985). Demonstration of serotoninergic axons terminating on luteinizing hormone-releasing hormone neurons in the preoptic area of the rat using a combination of immunocytochemistry and high resolution autoradiography. Neuroscience 14, 69-78. doi: 10.1016/0306-4522(85)90164-2

Knobil, E., and Neill, J. D. (2006). Knobil and Neill's Physiology of Reproduction. Amsterdam: Elsevier.

Koren, D., Egozi, Y., and Sokolovsky, M. (1992). Muscarinic involvement in the regulation of gonadotropin-releasing hormone in the cyclic rat. Mol. Cell. Endocrinol. 90, 87-93. doi: 10.1016/0303-7207(92)90105-F

Koussounadis, A., Langdon, S. P., Um, I. H., Harrison, D. J., and Smith, V. A. (2015). Relationship between differentially expressed mRNA and mRNAprotein correlations in a xenograft model system. Sci. Rep. 5:10775. doi: $10.1038 /$ srep 10775

Krsmanovic, L. Z., Mores, N., Navarro, C. E., Saeed, S. A., Arora, K. K., and Catt, K. J. (1998). Muscarinic regulation of intracellular signaling and neurosecretion in gonadotropin-releasing hormone neurons. Endocrinology 139, 4037-4043. doi: 10.1210/endo.139.10.6267
Lee, K., Porteous, R., Campbell, R. E., Lüscher, B., and Herbison, A. E. (2010). Knockdown of GABA(A) receptor signaling in GnRH neurons has minimal effects upon fertility. Endocrinology 151, 4428-4436. doi: 10.1210/en.2010-0314

Lee, W. S., Smith, M. S., and Hoffman, G. E. (1990). Luteinizing hormonereleasing hormone neurons express Fos protein during the proestrous surge of luteinizing hormone. Proc. Natl. Acad. Sci. U.S.A. 87, 5163-5167. doi: 10.1073/pnas.87.13.5163

Leranth, C., MacLusky, N. J., Sakamoto, H., Shanabrough, M., and Naftolin, F. (1985). Glutamic acid decarboxylase-containing axons synapse on LHRH neurons in the rat medial preoptic area. Neuroendocrinology 40, 536-539. doi: $10.1159 / 000124127$

Leranth, C., MacLusky, N. J., Shanabrough, M., and Naftolin, F. (1988). Catecholaminergic innervation of luteinizing hormone-releasing hormone and glutamic acid decarboxylase immunopositive neurons in the rat medial preoptic area. An electron-microscopic double immunostaining and degeneration study. Neuroendocrinology 48, 591-602. doi: 10.1159/000125068

Lin, D. M., Loveall, B., Ewer, J., Deitcher, D. L., and Sucher, N. J. (2007). "Characterization of mRNA expression in single neurons," in Neuroprotection Methods and Protocols, ed T. Borsello (Totowa, NJ: Humana Press), 133-152.

Liu, X., and Herbison, A. E. (2013). Dopamine regulation of gonadotropinreleasing hormone neuron excitability in male and female mice. Endocrinology 154, 340-350. doi: 10.1210/en.2012-1602

Liu, X., Porteous, R., d'Anglemont de Tassigny, X., Colledge, W. H., Millar, R., Petersen, S. L., et al. (2011). Frequency-dependent recruitment of fast amino acid and slow neuropeptide neurotransmitter release controls gonadotropinreleasing hormone neuron excitability. J. Neurosci. 31, 2421-2430. doi: 10.1523/JNEUROSCI.5759-10.2011

Livak, K. J., and Schmittgen, T. D. (2001). Analysis of relative gene expression data using real-time quantitative PCR and the 2(-Delta Delta C(T)) Method. Methods 25, 402-408. doi: 10.1006/meth.2001.1262

López, F. J., Donoso, A. O., and Negro-Vilar, A. (1990). Endogenous excitatory amino acid neurotransmission regulates the estradiol-induced LH surge in ovariectomized rats. Endocrinology 126, 1771-1773. doi: 10.1210/endo-1263-1771

López, F. J., Donoso, A. O., and Negro-Vilar, A. (1992). Endogenous excitatory amino acids and glutamate receptor subtypes involved in the control of hypothalamic luteinizing hormone-releasing hormone secretion. Endocrinology 130, 1986-1992.

Maier, T., Güell, M., and Serrano, L. (2009). Correlation of mRNA and protein in complex biological samples. FEBS Lett. 583, 3966-3973. doi: 10.1016/j.febslet.2009.10.036

Mathur, B. N., Capik, N. A., Alvarez, V. A., and Lovinger, D. M. (2011). Serotonin induces long-term depression at corticostriatal synapses. J. Neurosci. 31, 7402-7411. doi: 10.1523/JNEUROSCI.6250-10.2011

Merchenthaler, I., Kovács, G., Lavász, G., and Sétáló, G. (1980). The preopticoinfundibular LH-RH tract of the rat. Brain Res. 198, 63-74. doi: 10.1016/00068993(80)90344-3

Moenter, S. M., and Chu, Z. (2012). Rapid nongenomic effects of oestradiol on gonadotrophin-releasing hormone neurones. J. Neuroendocrinol. 24, 117-121. doi: $10.1111 / j .1365-2826.2011 .02135 . x$

Nelson, J. F., Felicio, L. S., Randall, P. K., Sims, C., and Finch, C. E. (1982). A longitudinal study of estrous cyclicity in aging C57BL/6J mice: I. Cycle frequency, length and vaginal cytology. Biol. Reprod. 27, 327-339. doi: 10.1095/biolreprod27.2.327

Nikolarakis, K. E., Loeffler, J. P., Almeida, O. F., and Herz, A. (1988). Pre- and postsynaptic actions of GABA on the release of hypothalamic gonadotropinreleasing hormone (GnRH). Brain Res. Bull. 21, 677-683. doi: 10.1016/03619230(88)90208-0

Norberg, R., Campbell, R., and Suter, K. J. (2013). Ion channels and information processing in GnRH neuron dendrites. Channels (Austin) 7, 135-145. doi: $10.4161 /$ chan. 24228

Okaty, B. W., Sugino, K., and Nelson, S. B. (2011). A quantitative comparison of cell-type-specific microarray gene expression profiling methods in the mouse brain. PLoS ONE 6:e16493. doi: 10.1371/journal.pone.0016493

Ottem, E. N., Godwin, J. G., Krishnan, S., and Petersen, S. L. (2004). Dual-phenotype GABA/glutamate neurons in adult preoptic area: sexual dimorphism and function. J. Neurosci. 24, 8097-8105. doi: 10.1523/JNEUROSCI.2267-04.2004 
Ottem, E. N., Godwin, J. G., and Petersen, S. L. (2002). Glutamatergic signaling through the $\mathrm{N}$-methyl-D-aspartate receptor directly activates medial subpopulations of luteinizing hormone-releasing hormone (LHRH) neurons, but does not appear to mediate the effects of estradiol on LHRH gene expression. Endocrinology 143, 4837-4845. doi: 10.1210/en.2002220707

Ping, L., Mahesh, V. B., Bhat, G. K., and Brann, D. W. (1997). Regulation of gonadotropin-releasing hormone and luteinizing hormone secretion by AMPA receptors. Evidence for a physiological role of AMPA receptors in the steroidinduced luteinizing hormone surge. Neuroendocrinology 66, 246-253. doi: $10.1159 / 000127245$

Ping, L., Mahesh, V. B., Wiedmeier, V. T., and Brann, D. W. (1994). Release of glutamate and aspartate from the preoptic area during the progesteroneinduced LH surge: in vivo microdialysis studies. Neuroendocrinology 59, 318-324. doi: 10.1159/000126673

Plant, T. M. (2015). 60 YEARS OF NEUROENDOCRINOLOGY: the hypothalamo-pituitary-gonadal axis. J. Endocrinol. 226, T41-T54. doi: 10.1530/joe-15-0113

Radovick, S., Levine, J. E., and Wolfe, A. (2012). Estrogenic regulation of the GnRH neuron. Front. Endocrinol. (Lausanne) 3:52. doi: 10.3389/fendo.2012.00052

R Core Team (2016). R: A Language and Environment for Statistical Computing. Vienna: R Foundation for Statistical Computing.

Richardson, S. B., Prasad, J. A., and Hollander, C. S. (1982). Acetylcholine, melatonin, and potassium depolarization stimulate release of luteinizing hormone-releasing hormone from rat hypothalamus in vitro. Proc. Natl. Acad. Sci. U.S.A. 79, 2686-2689. doi: 10.1073/pnas.79.8.2686

Ritchie, M. E., Phipson, B., Wu, D., Hu, Y., Law, C. W., Shi, W., et al. (2015). limma powers differential expression analyses for RNA-sequencing and microarray studies. Nucleic Acids Res. 43, e47. doi: 10.1093/nar/gkv007

Sales, G., Calura, E., Martini, P., and Romualdi, C. (2013). Graphite web: web tool for gene set analysis exploiting pathway topology. Nucleic Acids Res. 41, W89-W97. doi: 10.1093/nar/gkt386

Sarkar, D. K., Chiappa, S. A., Fink, G., and Sherwood, N. M. (1976). Gonadotropinreleasing hormone surge in pro-oestrous rats. Nature 264, 461-463. doi: $10.1038 / 264461 \mathrm{a} 0$

Sarkar, D. K., and Fink, G. (1980). Luteinizing hormone releasing factor in pituitary stalk plasma from long-term ovariectomized rats: effects of steroids. J. Endocrinol. 86, 511-524. doi: 10.1677/joe.0.0860511

Schwindinger, W. F., Mihalcik, L. J., Giger, K. E., Betz, K. S., Stauffer, A. M., Linden, J., et al. (2010). Adenosine A2A receptor signaling and golf assembly show a specific requirement for the gamma7 subtype in the striatum. J. Biol. Chem. 285, 29787-29796. doi: 10.1074/jbc.M110.142620

Sim, J. A., Skynner, M. J., Pape, J. R., and Herbison, A. E. (2000). Late postnatal reorganization of GABA(A) receptor signalling in native GnRH neurons. Eur. J. Neurosci. 12, 3497-3504. doi: 10.1046/j.1460-9568.2000.00261.x

Smith, M. J., and Jennes, L. (2001). Neural signals that regulate GnRH neurones directly during the oestrous cycle. Reproduction 122, 1-10. doi: 10.1530/rep.0.1220001

Soto, F., Garcia-Guzman, M., Gomez-Hernandez, J. M., Hollmann, M., Karschin, C., and Stühmer, W. (1996). P2X4: an ATP-activated ionotropic receptor cloned from rat brain. Proc. Natl. Acad. Sci. U.S.A. 93, 3684-3688. doi: 10.1073/pnas.93.8.3684

Spergel, D. J., Krüth, U., Hanley, D. F., Sprengel, R., and Seeburg, P. H. (1999). GABA- and glutamate-activated channels in green fluorescent protein-tagged gonadotropin-releasing hormone neurons in transgenic mice. J. Neurosci. 19, 2037-2050.

Stojilkovic, S. S. (2009). Purinergic regulation of hypothalamopituitary functions. Trends Endocrinol. Metab. 20, 460-468. doi: 10.1016/j.tem.2009.05.005

Suter, K. J., Song, W. J., Sampson, T. L., Wuarin, J. P., Saunders, J. T., Dudek, F. E., et al. (2000). Genetic targeting of green fluorescent protein to gonadotropin-releasing hormone neurons: characterization of whole-cell electrophysiological properties and morphology. Endocrinology 141, 412-419. doi: 10.1210/en.141.1.412

Tarca, A. L., Draghici, S., Khatri, P., Hassan, S. S., Mittal, P., Kim, J. S., et al. (2009). A novel signaling pathway impact analysis. Bioinformatics $25,75-82$. doi: 10.1093/bioinformatics/btn577
Temple, J. L., and Wray, S. (2005). Developmental changes in GABA receptor subunit composition within the gonadotrophin-releasing hormone-1 neuronal system. J. Neuroendocrinol. 17, 591-599. doi: 10.1111/j.1365-2826.2005.01348.x

Terasawa, E., Keen, K. L., Grendell, R. L., and Golos, T. G. (2005). Possible role of 5 -adenosine triphosphate in synchronization of $\mathrm{Ca}^{2+}$ oscillations in primate luteinizing hormone-releasing hormone neurons. Mol. Endocrinol. 19, 2736-2747. doi: 10.1210/me.2005-0034

Terasawa, E., Noel, S. D., and Keen, K. L. (2009). Rapid action of oestrogen in luteinising hormone-releasing hormone neurones: the role of GPR30. J. Neuroendocrinol. 21, 316-321. doi: 10.1111/j.1365-2826.2009.01839.x

Tin-Tin-Win-Shwe, Mitsushima, D., Shinohara, K., and Kimura, F. (2004). Sexual dimorphism of GABA release in the medial preoptic area and luteinizing hormone release in gonadectomized estrogen-primed rats. Neuroscience 127, 243-250. doi: 10.1016/j.neuroscience.2004.04.056

Todman, M. G., Han, S. K., and Herbison, A. E. (2005). Profiling neurotransmitter receptor expression in mouse gonadotropin-releasing hormone neurons using green fluorescent protein-promoter transgenics and microarrays. Neuroscience 132, 703-712. doi: 10.1016/j.neuroscience.2005.01.035

Turi, G. F., Liposits, Z., and Hrabovszky, E. (2008). Cholinergic afferents to gonadotropin-releasing hormone neurons of the rat. Neurochem. Int. 52, 723-728. doi: 10.1016/j.neuint.2007.09.001

Vastagh, C., Rodolosse, A., Solymosi, N., Farkas, I., Auer, H., Sárvári, M., et al. (2015). Differential gene expression in gonadotropin-releasing hormone neurons of male and metestrous female mice. Neuroendocrinology 102, 44-59. doi: $10.1159 / 000430818$

Vogel, C., and Marcotte, E. M. (2012). Insights into the regulation of protein abundance from proteomic and transcriptomic analyses. Nat. Rev. Genet. 13, 227-232. doi: $10.1038 / \mathrm{nrg} 3185$

Wada, K., Hu, L., Mores, N., Navarro, C. E., Fuda, H., Krsmanovic, L. Z., et al. (2006). Serotonin (5-HT) receptor subtypes mediate specific modes of 5-HTinduced signaling and regulation of neurosecretion in gonadotropin-releasing hormone neurons. Mol. Endocrinol. 20, 125-135. doi: 10.1210/me.2005-0109

Wang, H. J., Hoffman, G. E., and Smith, M. S. (1995). Increased GnRH mRNA in the GnRH neurons expressing cFos during the proestrous LH surge. Endocrinology 136, 3673-3676.

Wintermantel, T. M., Campbell, R. E., Porteous, R., Bock, D., Grone, H. J., Todman, M. G., et al. (2006). Definition of estrogen receptor pathway critical for estrogen positive feedback to gonadotropin-releasing hormone neurons and fertility. Neuron 52, 271-280. doi: 10.1016/j.neuron.2006.07.023

Wise, P. M. (1984). Estradiol-induced daily luteinizing hormone and prolactin surges in young and middle-aged rats: correlations with age-related changes in pituitary responsiveness and catecholamine turnover rates in microdissected brain areas. Endocrinology 115, 801-809. doi: 10.1210/endo-115-2-801

Xu, Y., Sheng, H., Bao, Q., Wang, Y., Lu, J., and Ni, X. (2016). NLRP3 inflammasome activation mediates estrogen deficiency-induced depressionand anxiety-like behavior and hippocampal inflammation in mice. Brain Behav. Immun. 56, 175-186. doi: 10.1016/j.bbi.2016.02.022

Yeo, S. H., and Herbison, A. E. (2014). Estrogen-negative feedback and estrous cyclicity are critically dependent upon estrogen receptor-alpha expression in the arcuate nucleus of adult female mice. Endocrinology 155, 2986-2995. doi: 10.1210/en.2014-1128

Zhang, C., Bosch, M. A., Ronnekleiv, O. K., and Kelly, M. J. (2009). Gammaaminobutyric acid $\mathrm{B}$ receptor mediated inhibition of gonadotropin-releasing hormone neurons is suppressed by kisspeptin-G protein-coupled receptor 54 signaling. Endocrinology 150, 2388-2394. doi: 10.1210/en.2008-1313

Conflict of Interest Statement: The authors declare that the research was conducted in the absence of any commercial or financial relationships that could be construed as a potential conflict of interest.

Copyright $\odot 2016$ Vastagh, Rodolosse, Solymosi and Liposits. This is an open-access article distributed under the terms of the Creative Commons Attribution License (CC $B Y)$. The use, distribution or reproduction in other forums is permitted, provided the original author(s) or licensor are credited and that the original publication in this journal is cited, in accordance with accepted academic practice. No use, distribution or reproduction is permitted which does not comply with these terms. 